Article

\title{
Energy-Efficient Direct Yaw Moment Control for In-Wheel Motor Electric Vehicles Utilising Motor Efficiency Maps
}

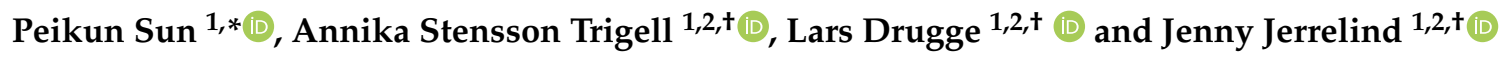 \\ 1 KTH Vehicle Dynamics, Department of Engineering Mechanics, KTH Royal Institute of Technology, \\ SE-100 44 Stockholm, Sweden; annika@kth.se (A.S.T.); larsd@kth.se (L.D.); jennyj@kth.se (J.J.) \\ 2 Centre for ECO2 Vehicle Design, KTH Royal Institute of Technology, SE-100 44 Stockholm, Sweden \\ * Correspondence: peikun@kth.se; Tel.: +46-738926676 \\ $\dagger$ These authors contributed equally to this work.
}

Received: 12 December 2019; Accepted: 21 January 2020; Published: 28 January 2020

\begin{abstract}
An active energy-efficient direct yaw moment control (DYC) for in-wheel motor electric vehicles taking motor efficiency maps into consideration is proposed in this paper. The potential contribution of DYC to energy saving during quasi-steady-state cornering is analysed. The study in this paper has produced promising results which show that DYC can be used to reduce the power consumption while satisfying the same cornering demand. A controller structure that includes a driver model and an offline torque distribution law during continuous driving and cornering is developed. For comparison, the power consumption of stability DYC is also analysed. Simulations for double lane change manoeuvres are performed and driving conditions either with a constant velocity or with longitudinal acceleration are designed to verify the effectiveness of the proposed controller in different driving situations. Under constant velocity cornering, since the total torque demand is not high, two rear wheels are engaged and during cornering it is beneficial to distribute more torque to one wheel to improve energy efficiency. In the simulated driving manoeuvres, up to $10 \%$ energy can be saved compared to other control methods. During acceleration in cornering, since the total torque demand is high, it is energy-efficient to use all the four in-wheel motors during cornering.
\end{abstract}

Keywords: electric vehicles; energy efficiency; direct yaw moment control; motor efficiency map; in-wheel motor technology

\section{Introduction}

Electric vehicles have attracted a great deal of attention and are widely used nowadays. Due to their limited driving range and the high cost of their batteries, energy-efficient control of electric vehicles is considered a very important research field. A new electric vehicle powertrain architecture realised by in-wheel motor technology, especially four in-wheel motors (4IWM), displays the possibility of achieving a more flexible torque distribution than that achieved in traditional centralised driving vehicles. 4IWM electric vehicles have more control variables than the number of relevant independently controlled generalised coordinates and can be called over-actuated electric vehicles.

Since the torque of each wheel is directly controlled, direct yaw moment control (DYC) can easily be carried out by 4IWM electric vehicles. One advantage of DYC is that it can provide an effective way to stabilise the vehicles. Stability DYC for in-wheel motor electric vehicles has been studied by some researchers [1-3]. In addition to enhancing the stability, through proper distribution of the wheel torques, DYC can reduce the power consumption. During vehicle cornering, tyre slip loss can be a large proportion of the total power loss [4]. Kobayashi et al. [5,6] studied how DYC changes 
the cornering resistance and developed an energy-efficient DYC which can minimise the tyre slip loss thereby reducing the energy consumption during vehicle cornering. Using DYC is an active way to reduce the energy consumption, however, motor efficiency maps were not considered in the studies. Edrén et al. [7] studied how active steering and DYC can be utilised to improve the vehicle cornering efficiency, however, in the first place, motor efficiency maps were not considered; in the second place, the percentage of energy saving was limited if one takes the rolling resistance and air drag into consideration. Several researchers have studied hierarchical control structures consisting of a high-level stability control and a low-level energy-efficient torque distribution control [8-10]. In these studies, based on a reference model, the high-level controller determined the stability yaw moment and using a motor efficiency map, the low-level controller optimised the energy-efficient torque distribution based on the desired yaw moment and total torque demand. Although motor efficiency maps were considered, the energy-efficient control was achieved by the low-level controller rather than the high-level controller, and this is a passive way to save energy. In research works [11-13], power loss of an electric drivetrain under different work load and different velocity is developed and the hierarchical structure is also used in these works. The function of the high-level controller is to track the reference yaw rate and the lower level control distributes the torques based on the power loss characterstics. Under each control step, the yaw moment $M_{z}$ is a fixed value according to the reference yaw rate. It is also a passive way to save energy. There are also some researchers who have studied the energy-efficient control of 4IWM and steer-by-wire electric vehicles [14,15]. However, these researchers also followed the hierarchical DYC control method, with stability control being achieved by the high-level controller.

Although stability control is prioritised, the average driver generally drives below a lateral acceleration of $4 \mathrm{~m} / \mathrm{s}^{2}$ (on high friction road) [16] which represents a normal and non-safety-critical driving behaviour. It is only during certain critical manoeuvres that the electronic stability program (ESP) will be triggered $[17,18]$. During non-safety-critical driving manoeuvres, energy-efficient driving should play the dominant role as long as it does not cause potential stability issues. Therefore, in this paper, an active energy-efficient DYC method taking into account motor efficiency maps is proposed for 4IWM electric vehicles. The hierarchical structure introduced above can only provide fixed $M_{z}$ for each time step. The active energy-efficient DYC method proposed in this work can provide a range of $M_{z}$ to choose from. The influence of this active energy-efficient DYC method on vehicle stability is also considered.

An outline of this paper follows. First, the vehicle model and the Magic Formula tyre models for the longitudinal and lateral forces are presented. The design of the motor efficiency maps is then described. In Section 5, the potential effect of active DYC on energy saving during quasi-steady-state cornering is analysed. The design of a driver model consisting of a speed control part and a direction control part is thereafter presented. The attention is focused on the calculation of the yaw moment range based on the desired lateral acceleration. Subsequently, optimisations were performed to explore the offline torque distribution rules of the motor efficiency maps. The creation of the controller structure with Golden Section Search optimisation is then presented. The focus then turns to the results of simulations carried out at a constant velocity and acceleration when driving through double lane change manoeuvres, with the aim of verifying the effectiveness of the proposed controller during continuous driving and cornering. Finally, conclusions drawn from the study presented in this paper are provided, as well as proposals for future research.

\section{Vehicle Model}

In this study, a two-track vehicle model shown in Figure 1 is developed and front wheel steering is adopted. The longitudinal, lateral and yaw motions are formulated as

$$
m a_{x}=F_{x 1} \cos \delta_{f}+F_{x 2} \cos \delta_{f}+F_{x 3}+F_{x 4}-F_{y 1} \sin \delta_{f}-F_{y 2} \sin \delta_{f}-F_{a r}
$$




$$
\begin{gathered}
m a_{y}=F_{x 1} \sin \delta_{f}+F_{x 2} \sin \delta_{f}+F_{y 1} \cos \delta_{f}+F_{y 2} \cos \delta_{f}+F_{y 3}+F_{y 4} \\
I_{z} \ddot{\psi}=\left(F_{x 1} \sin \delta_{f}+F_{x 2} \sin \delta_{f}+F_{y 1} \cos \delta_{f}+F_{y 2} \cos \delta_{f}\right) l_{f}-\left(F_{y 3}+F y 4\right) l_{r} \\
+\left(F_{x 2} \cos \delta_{f}-F_{y 2} \sin \delta_{f}-F_{x 1} \cos \delta_{f}+F_{y 1} \sin \delta_{f}+F_{x 4}-F_{x 3}\right) t_{w} / 2
\end{gathered}
$$

where $a_{x}$ is the longitudinal acceleration $\left(a_{x}=v_{x}-v_{y} \dot{\psi}\right), a_{y}$ is the lateral acceleration $\left(a_{y}=v_{y}+v_{x} \dot{\psi}\right)$, $m$ is the vehicle mass, $v_{x}$ is the longitudinal velocity, $v_{y}$ is the lateral velocity, $\psi$ is the yaw angle, $F_{x 1}$, $F_{x 2}, F_{x 3}$ and $F_{x 4}$ are longitudinal forces at each tyre respectively, $F_{y 1}, F_{y 2}, F_{y 3}$ and $F_{y 4}$ are lateral forces at each tyre respectively, $F_{a r}$ is the aerodynamic resistance, $\delta_{f}$ is the steering angle for the front wheels, $I_{z}$ is the moment of yaw inertia, $l_{f}$ is the distance from centre of gravity $(\mathrm{CoG})$ to front axle, $l_{r}$ is distance from CoG to rear axle and $t_{w}$ is the wheel track width (the subscript, 1: front left; 2 : front right; 3 : rear left; 4: rear right).

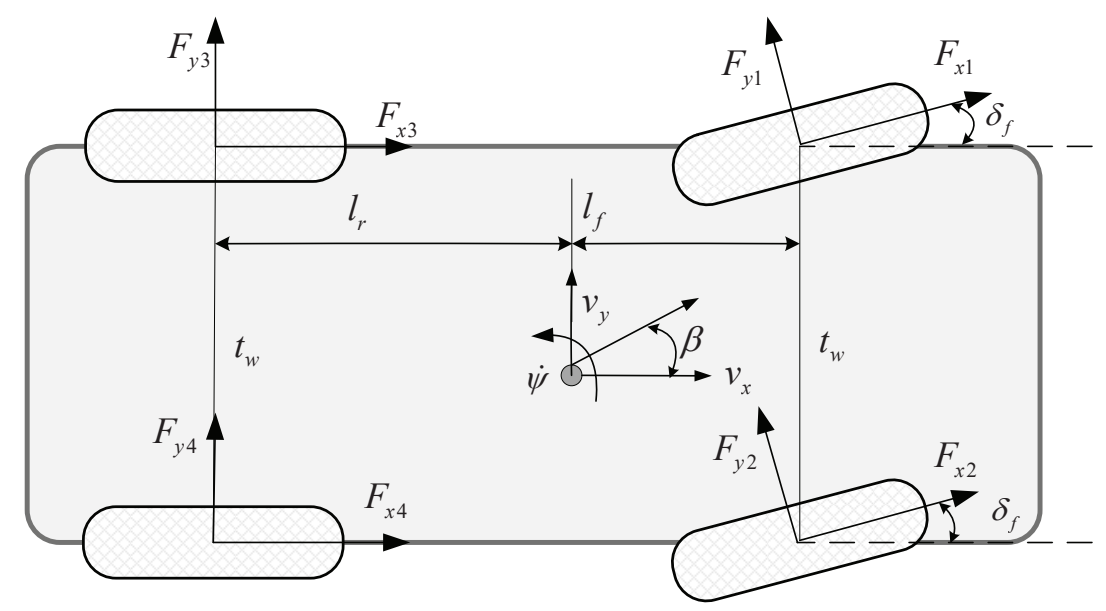

Figure 1. Two-track vehicle model.

The tyre slip angles $\alpha_{1}, \alpha_{2}, \alpha_{3}$ and $\alpha_{4}$ are expressed as

$$
\left\{\begin{array}{rlrl}
\alpha_{1} & =\frac{v_{y}+\dot{\psi} l_{f}}{v_{x}-\dot{\psi} t_{w} / 2}-\delta_{f} ; \alpha_{2} & =\frac{v_{y}+\dot{\psi} l_{f}}{v_{x}+\dot{\psi} t_{w} / 2}-\delta_{f} \\
\alpha_{3} & =\frac{v_{y}-\dot{\psi} l_{r}}{v_{x}-\dot{\psi} t_{w} / 2} ; & \alpha_{4} & =\frac{v_{y}-\dot{\psi} l_{r}}{v_{x}+\dot{\psi} t_{w} / 2}
\end{array}\right.
$$

The equation for the forward speed of each individual wheel can be expressed as

$$
\begin{cases}v_{1}=v_{x}-\dot{\psi} t_{w} / 2 ; & v_{2}=v_{x}+\dot{\psi} t_{w} / 2 \\ v_{3}=v_{x}-\dot{\psi} t_{w} / 2 ; & v_{4}=v_{x}+\dot{\psi} t_{w} / 2\end{cases}
$$

The angular velocity of the $i^{\text {th }}$ wheel can be expressed as

$$
\omega_{i}=\left(1+\kappa_{i}\right) v_{i} / R_{0}
$$

where $\kappa_{i}$ is the slip ratio and $R_{0}$ is the effective radius of the tyre. 
The vertical forces of each wheel are expressed as

$$
\left\{\begin{array}{l}
F_{z 1}=m\left(\frac{1}{2} g l_{r}-\frac{1}{2} a_{x} h-\frac{l_{r}}{t_{w}} a_{y} h\right) /\left(l_{f}+l r\right) \\
F_{z 2}=m\left(\frac{1}{2} g l_{r}-\frac{1}{2} a_{x} h+\frac{l_{r}}{t_{w}} a_{y} h\right) /\left(l_{f}+l r\right) \\
F_{z 3}=m\left(\frac{1}{2} g l_{f}+\frac{1}{2} a_{x} h-\frac{l_{f}}{t_{w}} a_{y} h\right) /\left(l_{f}+l r\right) \\
F_{z 4}=m\left(\frac{1}{2} g l_{f}+\frac{1}{2} a_{x} h+\frac{l_{f}}{t_{w}} a_{y} h\right) /\left(l_{f}+l r\right)
\end{array}\right.
$$

where $g$ is the gravitational acceleration and $h$ is the height of CoG.

The equations of tyre's motion in the longitudinal direction can be written as

$$
T_{i}-f_{r r} F_{z i} R_{0}-F_{x i} R_{0}=I_{w} \dot{\omega}_{i}
$$

where $T_{i}$ is the driving torque, $f_{r r}$ is the rolling resistance coefficient and $I_{w}$ is the rotational inertia of the wheel.

The aerodynamic resistance $F_{a r}$ can be expressed as

$$
F_{a r}=0.5 C_{a r} \rho A v_{x}^{2}
$$

where $C_{a r}$ is the coefficient of aerodynamic resistance, $\rho$ is the density of the air and $A$ is the frontal area of the vehicle.

The vehicle is designed to be a four-in-wheel-motor electric vehicle and the chosen vehicle parameters are shown in Table 1.

Table 1. Vehicle parameters.

\begin{tabular}{cccccccc}
\hline Parameter & Value & Parameter & Value & Parameter & Value & Parameter & Value \\
\hline$m$ & $1500 \mathrm{~kg}$ & $l_{r}$ & $1.5 \mathrm{~m}$ & $l_{f}$ & $1.2 \mathrm{~m}$ & $I_{z}$ & $1700 \mathrm{~kg} / \mathrm{m}^{2}$ \\
$t_{w}$ & $1.65 \mathrm{~m}$ & $I_{w}$ & $1 \mathrm{~kg} / \mathrm{m}^{2}$ & $h$ & $0.48 \mathrm{~m}$ & $R_{0}$ & $0.3 \mathrm{~m}$ \\
$C_{a r}$ & 0.3 & $A$ & $2 \mathrm{~m}^{2}$ & $f_{r r}$ & 0.01 & & \\
\hline
\end{tabular}

\section{Tyre Models}

In the present study, Magic Formula tyre models for the longitudinal force and the lateral force are used. The Magic Formula is a semi-empirical equation that can closely match experimental data [19]. The specific coefficients are derived from Appendix 3 of Pacejka [19] and are listed in Table 2. The equation for the longitudinal tyre force $F_{x}$ can be expressed as

$$
F_{x}=\mu F_{z} \sin \left[p_{c x 1} \arctan \left(B_{x} \kappa-E_{x}\left(B_{x} \kappa-\arctan \left(B_{x} \kappa\right)\right)\right)\right]
$$

where $\mu$ is the road friction and $B_{x}$ and $E_{x}$ can be expressed as

$$
\begin{gathered}
B_{x}=K_{x \kappa} /\left(p_{c x 1} \mu F_{z}\right) \\
K_{x \kappa}=F_{z}\left(p_{k x 1}+p_{k x 2} d f_{z}\right) \exp \left(p_{k x 3} d f_{z}\right) \\
E_{x}=\left(p_{e x 1}+p_{e x 2} d f_{z}+p_{e x 3} d f_{z}^{2}\right)\left(1-p_{e x 4} \operatorname{sign}(\kappa)\right) \\
d f_{z}=\left(F_{z}-F_{z 0}\right) /\left(F_{z 0}\right)
\end{gathered}
$$

where $F_{z 0}=4000 \mathrm{~N}$. 
The equation for the lateral tyre force $F_{y}$ can be expressed as

$$
F_{y}=\mu F_{z} \sin \left[p_{c y 1} \arctan \left(B_{y} \alpha-E_{y}\left(B_{y} \alpha-\arctan \left(B_{y} \alpha\right)\right)\right)\right]
$$

where $\alpha$ is the slip angle of the tyre and $B_{y}, E_{y}$ are expressed as

$$
\begin{gathered}
B_{y}=K_{y \alpha} /\left(p_{c y 1} \mu F_{z}\right) \\
E_{y}=\left(p_{e y 1}+p_{e y 2} d f_{z}\right)\left(1-p_{e y 3} \operatorname{sign}(\alpha)\right) \\
K_{y \alpha}=F_{z 0} p_{k y 1} \sin \left[p_{k y 4} \arctan \left(F_{z} /\left(F_{z 0} p_{k y 2}\right)\right)\right]
\end{gathered}
$$

Table 2. Tyre force coefficients.

\begin{tabular}{cccccccc}
\hline Coefficient & Value & Coefficient & Value & Coefficient & Value & Coefficient & Value \\
\hline$p_{c x 1}$ & 1.579 & $p_{e x 1}$ & 0.11113 & $p_{e x 2}$ & 0.3143 & $p_{e x 3}$ & 0 \\
$p_{e x 4}$ & 0.001719 & $p_{k x 1}$ & 21.687 & $p_{k x 2}$ & 13.728 & $p_{k x 3}$ & -0.4098 \\
$p_{c y 1}$ & 1.388 & $p_{k y 1}$ & -15.324 & $p_{k y 2}$ & 1.715 & $p_{k y 4}$ & 2.0005 \\
$p_{e y 1}$ & -0.8057 & $p_{e y 2}$ & -0.6046 & $p_{e y 3}$ & 0.09854 & & \\
\hline
\end{tabular}

\section{Motor Efficiency Maps}

The total torque of the four in-wheel motors should achieve certain performance comprising slope starting ability and longitudinal acceleration-maintaining ability. Firstly, the parking system of the vehicle is designed to be able to keep a vehicle in place on a slope of at least $18 \%$ [20]. The vehicle is therefore designed to start from an $18 \%$ slope at $0 \mathrm{~km} / \mathrm{h}$ with a longitudinal acceleration of $0.2 \mathrm{~m} / \mathrm{s}^{2}$ corresponding to a total torque demand of $916.3 \mathrm{Nm}$. Secondly, the vehicle is designed to be able to maintain a longitudinal acceleration of $2 \mathrm{~m} / \mathrm{s}^{2}$ at $80 \mathrm{~km} / \mathrm{h}$ with a total torque demand of $987.1 \mathrm{Nm}$.

Electric motor efficiency maps are functions of torque and speed. This work focuses on the control method and a small velocity range is studied. Therefore, the assumption is that within this limited speed range, the characteristic of the motor efficiency map is only a function of torque. Based on the characteristics of in-wheel motor data in Chen and Wang [8], two simplified in-wheel motor efficiency maps are designed where the efficiency is a function of the motor torque and the inverter loss is included in these maps. These two motor efficiency maps are scaled up compared to the motor in [8] to meet the slope and acceleration torque demand. In Figure 2, it can be observed that the maximum driving torque of the first designed motor (Motor I) is $250 \mathrm{Nm}$ and the maximum braking torque is $-125 \mathrm{Nm}$. With Motor I, the total maximum driving torque of the four wheels is $1000 \mathrm{Nm}$, which is very close to the torque demand of $987.1 \mathrm{Nm}$. A larger torque margin is also considered to allow for manoeuvres demanding an even higher torque. Motor II in Figure 2 whose torque range is from $-200 \mathrm{Nm}$ to $400 \mathrm{Nm}$ is therefore also considered.

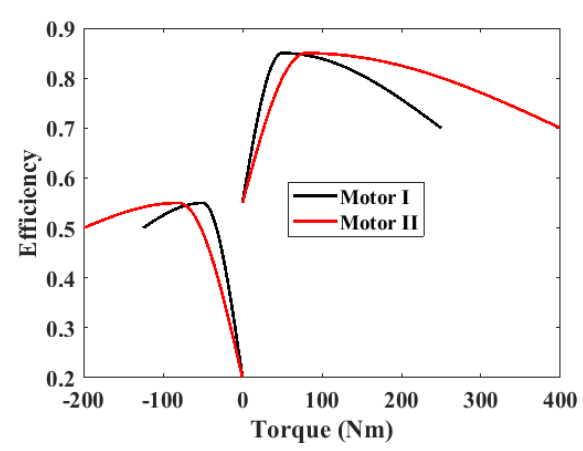

Figure 2. Two designed motor efficiency maps. 


\section{Potential of Energy-Efficient Torque Distribution Control during Steady-State Cornering}

Four choices of torque distribution have been compared while driving in a corner, namely, (1) front two-wheel equal torque drive, (2) rear two-wheel equal torque drive, (3) all four-wheel equal torque drive and (4) active DYC. With DYC, there is a potential for distributing the torques of the four wheels so that the vehicle can fully utilise the motor efficiency to consume less energy while satisfying the same driving demand.

During cornering, transient cornering and steady-state cornering can occur. As is introduced in [21], the cornering curvature $\xi$ and $\beta$ are taken as state variables for transient cornering. During steady-state cornering, $v_{x}$ and $\dot{\psi}$ are taken as state variables. While driving in a circle at constant velocity, $\dot{\psi}$ can be constant, however, $\beta$ changes with different $M_{z}$. When analysing DYC, it is beneficial to use $v_{x}$ and $\dot{\psi}$ as state variables. Although the steady-state cornerings are the equilibrium points of a transient behaviour, by analysing the vehicle characteristics in steady-state cornering, the fundamental vehicle motion characteristics can be understood [22]. Steady-state and quasi-steady-state cornering are also used in research works $[5,6]$ to analyse the potential of DYC on energy saving during cornering. Therefore, quasi-steady-state cornering (when $v_{x}=0$, it is steady-state) is adopted in this study.

During quasi-steady-state cornering, it can be assumed that $v_{y}=0$ and $\ddot{\psi}=0$. Since $I_{w} \dot{\omega}_{i}$ is very small, $I_{w} \dot{\omega}_{i}$ is assumed to be zero. The steering angle is also assumed to be small. Equations (1)-(3) and (8) can be reformulated as

$$
\begin{aligned}
m\left(v_{x}-v_{y} \dot{\psi}\right)= & \left(T_{a l l}-m g f_{r} r R_{0}\right) / R_{0}-F_{y 1} \sin \delta_{f}-F_{y 2} \sin \delta_{f}-F_{a r} \\
& m v_{x} \dot{\psi}=F_{y 1}+F_{y 2}+F_{y 3}+F_{y 4} \\
0= & \left(F_{y 1}+F_{y 2}\right) l_{f}-\left(F_{y 3}+F_{y 4}\right) l_{r}+M_{z}
\end{aligned}
$$

where $T_{\text {all }}$ is the total torque, $T_{\text {all }}=T_{1}+T_{2}+T_{3}+T_{4}$ and $M_{z}$ is the yaw moment, $M_{z}=\left(F_{x 2}+F_{x 4}-F_{x 1}-F_{x 3}\right) \times t_{w} / 2$.

The longitudinal slip ratios $\kappa_{i}$ are considered to be small and from Equation (6), the angular velocity of the $i$ th wheel can be expressed as $\omega_{i} \approx v_{i} / R_{0}$. The optimisation goal is to minimise the power consumption of all four wheels $P$ which can be expressed as

$$
P=\sum_{i=1}^{4} T_{i} \omega_{i}\left(\frac{1+\operatorname{sign}\left(T_{i}\right)}{2} \frac{1}{\eta\left(T_{i}\right)}+\frac{1-\operatorname{sign}\left(T_{i}\right)}{2} \eta\left(T_{i}\right)\right)
$$

where $\eta$ is the motor efficiency as a function of $T_{i}$.

From Equations (18)-(20), $T_{\text {all }}$ can be deduced with a given $v_{x}, v_{x}, a_{y}$ and $M_{z}$. In order to explore the potential effect of DYC on energy saving, two kinds of driving scenarios are analysed, namely constant velocity cornering and cornering with acceleration. For constant velocity cornering, $v_{x}=0 \mathrm{~m} / \mathrm{s}^{2}$ and $v_{x}=50 \mathrm{~km} / \mathrm{h}$ are used. During cornering with acceleration, $v_{x}=0.6 \mathrm{~m} / \mathrm{s}^{2}$ and $v_{x}=50 \mathrm{~km} / \mathrm{h}$ are used. The range of the yaw moment $M_{z}$ is from $-1000 \mathrm{Nm}$ to $1000 \mathrm{Nm}$ and the range of $a_{y}$ is from $0.1 \mathrm{~m} / \mathrm{s}^{2}$ to $4 \mathrm{~m} / \mathrm{s}^{2}$. The optimisation procedure is shown in Figure 3. Particle Swarm Optimisation is used to calculate the minimal power usage under a given specific $M_{z}$. The optimisation interval for $M_{z}$ is $2 \mathrm{Nm}$.

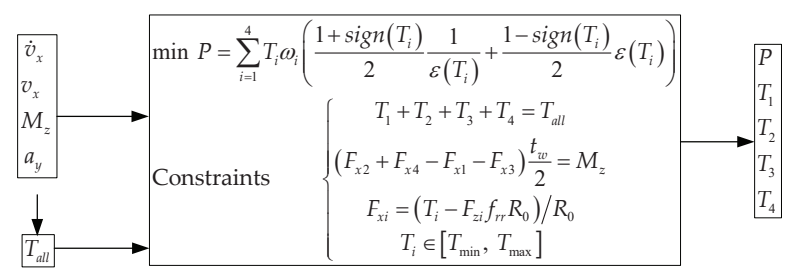

Figure 3. Minimal power optimisation procedure under $M_{z}$. 


\subsection{Constant Velocity Cornering}

The power loss for front two-wheel equal torque driving and that for rear two-wheel equal torque driving are almost the same, and therefore they are in this paper considered to be the same, namely, two-wheel equal torque driving (2WETD). Compared to equal torque driving, the percentage of energy saving $\epsilon$ with active DYC can be described as

$$
\epsilon=\left(P_{e}-P_{a}\right) / P_{e} \times 100
$$

where $P_{e}$ is the power consumption of 2WETD or four-wheel equal torque driving (4WETD) and $P_{a}$ is the power consumption of DYC.

The optimisation results for Motor I for constant velocity cornering are shown in Figure 4. In Figure 4a, it can be seen that there are two local minimal power usage lines during the whole range of $a_{y}$. In Figure $4 \mathrm{~b}$, it can be seen that DYC can save considerable percentage of energy at the two local minimal power usage lines compared to $2 \mathrm{WETD}$ and WWETD. The front steering angle changes are shown in Figure $4 \mathrm{c}$ and the total torque changes are shown in Figure $4 \mathrm{~d}$. Under each $a_{y}$, the total torque does not change tremendously with $M_{z}$. The optimal torque distributions are shown in Figure 4e.

The results for Motor II are shown in Figure 5 and are generally similar to those of Motor I in Figure 4. The steering angle changes and total torque changes of Motor II is the same with those for Motor I. From Figure $5 b$, it is seen that DYC can also save considerable percentage of energy compared to both 2WETD and 4WETD.

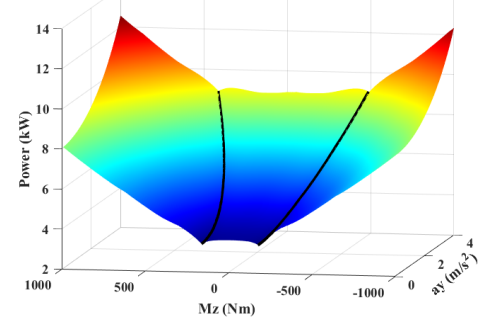

(a)

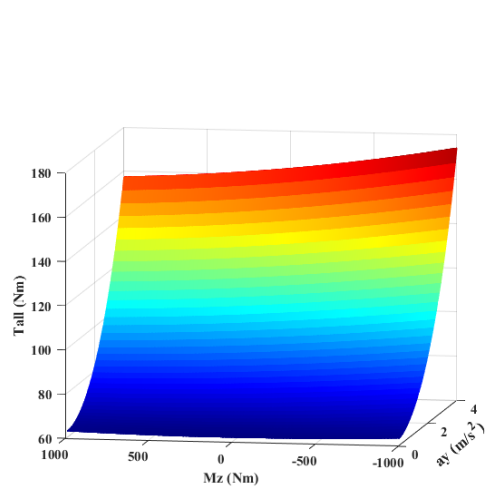

(d)

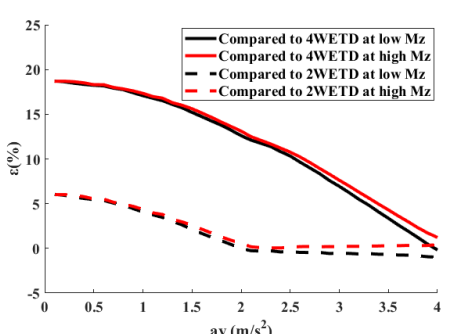

(b)

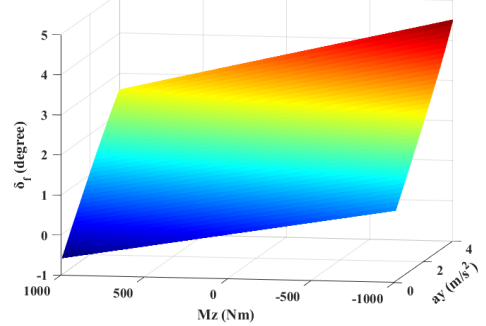

(c)
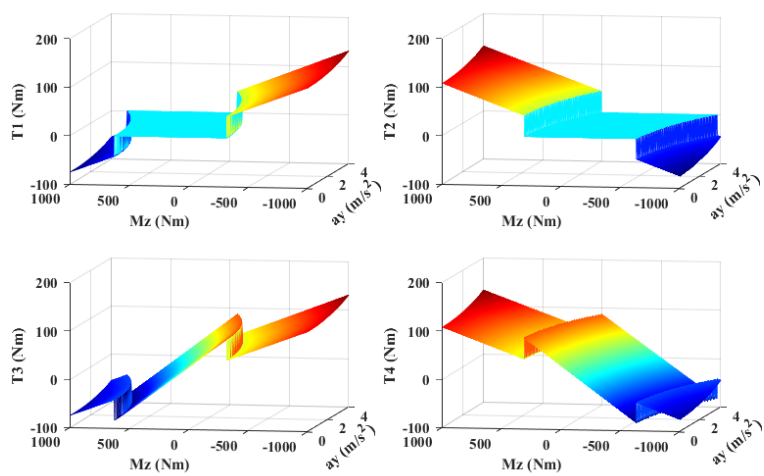

(e)

Figure 4. Results for constant velocity cornering with Motor I: (a) Minimal power; (b) Percentage of energy saving; (c) Steering angle; (d) Total torque; (e) Optimal wheel torques. 


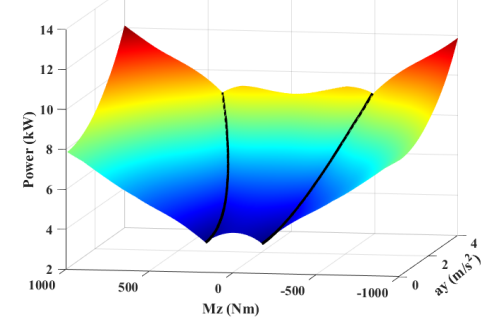

(a)

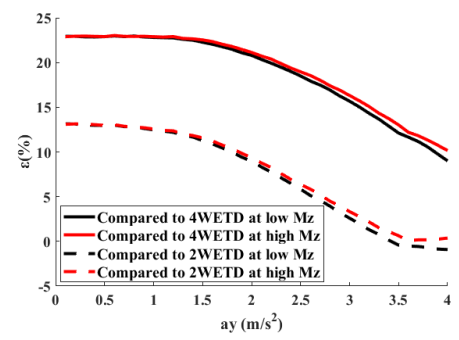

(b)
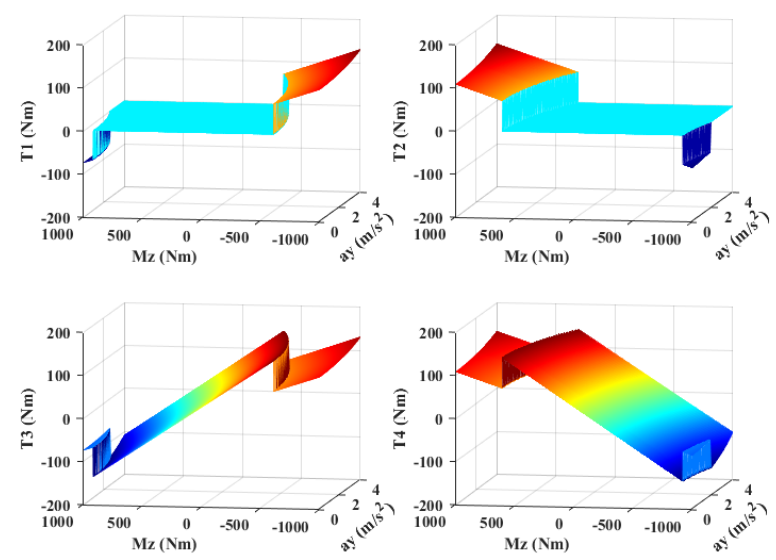

(c)

Figure 5. Results versus $M_{z}$ for constant velocity cornering with Motor II: (a) Minimal power; (b) Percentage of energy saving; (c) Optimal wheel torques.

\subsection{Cornering with Acceleration}

The results for Motor I during cornering with acceleration are shown in Figure 6. The dark line in Figure 6 a represents the minimal power points. Combining Figure $6 a, b$, it can be seen that DYC adopting 4WETD consumes the minimum. Compared to 2WETD, DYC can achieve more than $6 \%$ reduction in the power consumption. The results for Motor II are shown in Figure 7, which are similar to the results of Motor I.

The optimisation results show that DYC can be used to reduce the power consumption during constant cornering. Figures 4 and 5 show that the total torque demand is small and by combining the motor efficiency maps in Figure 2, 2WETD and 4WETD will result in a low overall motor efficiency. However, active DYC can lead to a high motor efficiency. During cornering with acceleration, the total torque demand is high and 4WETD can, consequently, maintain a high motor efficiency.

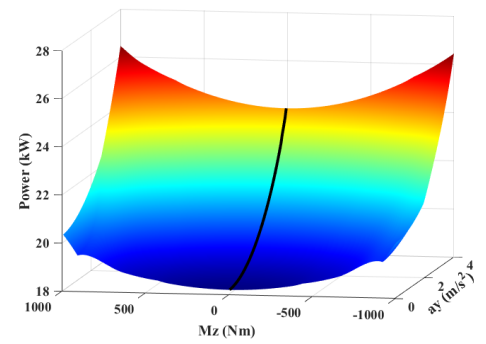

(a)

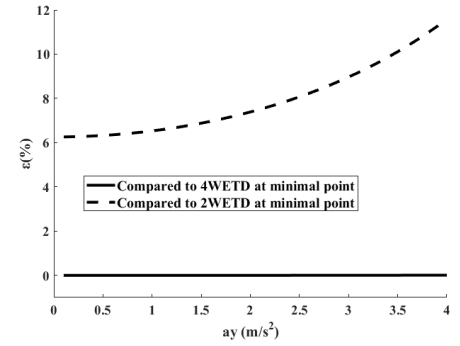

(b)

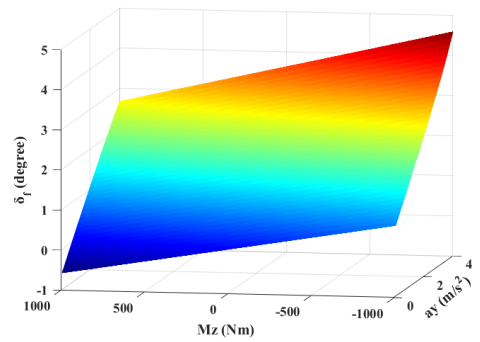

(c)

Figure 6. Cont. 


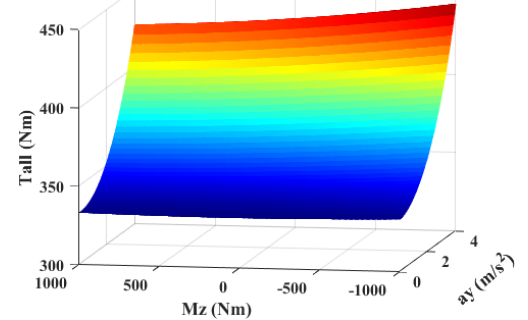

(d)
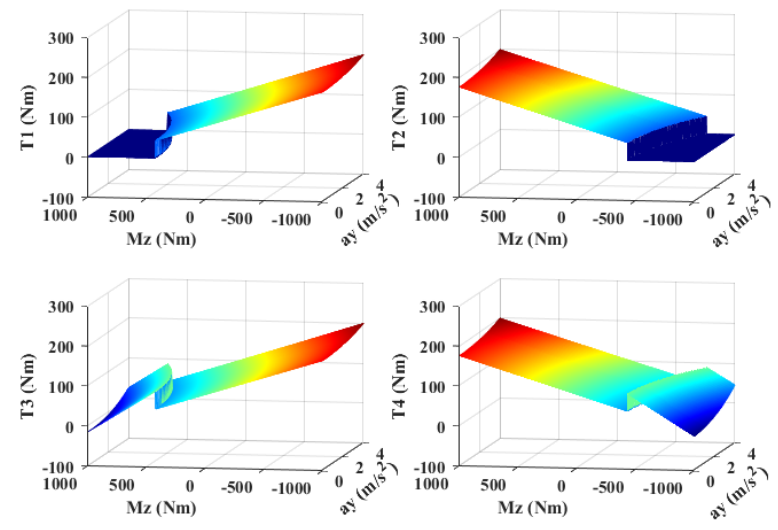

(e)

Figure 6. Results for acceleration during cornering with Motor I: (a) Minimal power; (b) Percentage of energy saving; (c) Steering angle; (d) Total torque; (e) Optimal wheel torques.

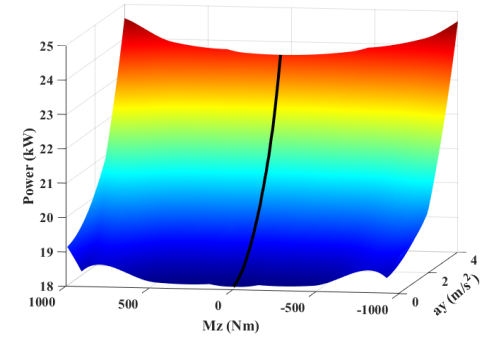

(a)

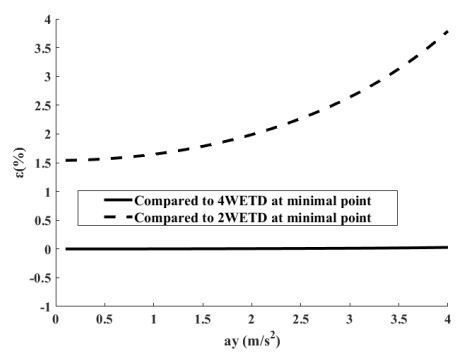

(b)
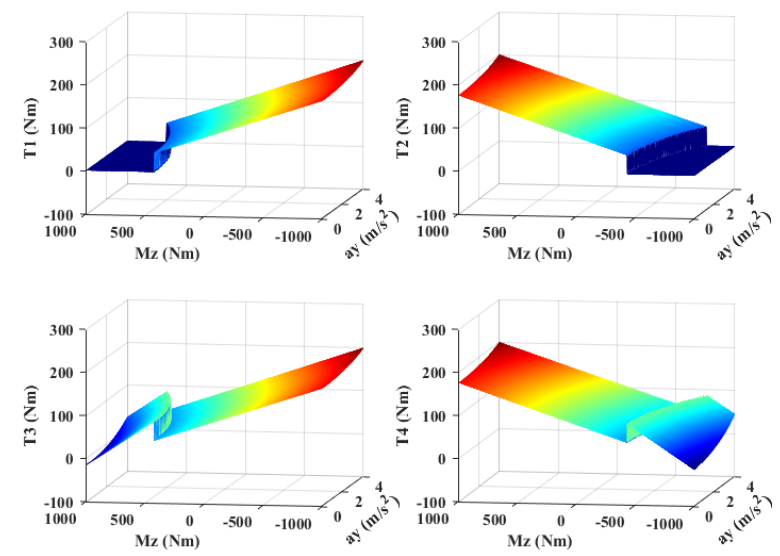

(c)

Figure 7. Results for acceleration during cornering with Motor II: (a) Minimal power; (b) Percentage of energy saving; (c) Optimal wheel torques.

\section{Controller Design}

To be able to compare active energy-efficient DYC with stability DYC and equal torque driving, these three driving strategies should be applied with the vehicle driving at the same velocity and following the same path. In Figure 4c, it can be seen that active DYC causes a change in the steering angle, and to avoid counter-steering, the steering angle should follow the same direction with the lateral acceleration. Meanwhile, the yaw moment range, torque change rate and steering angle change rate should also be considered with active DYC. For comparison, stability DYC is designed and the power usage of stability DYC is analysed. 


\subsection{Driver Model}

The driver model consists of two parts: velocity control and direction control. A PID velocity controller is adopted to reach and maintain the desired velocity. A multi-point preview steering model [23-25] is used to follow the desired path which is illustrated in Figure 8. $P_{1}$ is the closest road point to the current vehicle position; $d_{y 1}$ is the distance between these two points on the $y$ axis (the vehicle coordinator); $P_{0}$ is the preview point at time $T_{p}$ and $P_{2}$ is the closest point on the road to $P_{0}$; $d y_{2}$ is the distance between $P_{0}$ and $P_{2}$ on the $y$ axis; and $\psi_{r}$ is the road tangent angle at $P_{2}$. The steering angle can be expressed as

$$
\delta_{f}=K_{1} d y_{1}+K_{2} d y_{2}+K_{3}\left(\psi_{r}-\psi\right)
$$

where $K_{1}, K_{2}$ and $K_{3}$ are coefficients.

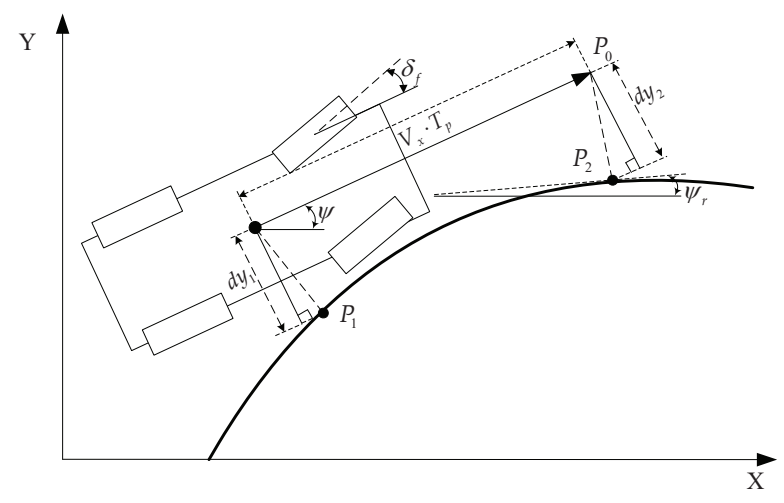

Figure 8. Multi-point steering model.

The understeer gradient of the studied vehicle is small. Therefore, for simplicity, the desired lateral acceleration $a_{y r}$ [22] as a function of $v_{x}$ and $\delta_{f}$ can be expressed as

$$
a_{y r}=v_{x}^{2} /\left(L / \delta_{f}\right)
$$

\subsection{Yaw Moment Range}

In order to build the relationship between the steering angle and the yaw moment, the bicycle model is used and a linear lateral tyre model is adopted. Without consideration of the yaw acceleration, the following equations are developed

$$
\begin{gathered}
m a_{y}=F_{y 12}+F_{y 34} \\
0=l_{f} F_{y 12}-l_{r} F_{y 34}+M_{z}
\end{gathered}
$$

$F_{y 12}$ and $F_{y 34}$ can be expressed as

$$
\begin{gathered}
F_{y 12}=C_{f}\left(\beta+l_{f} \dot{\psi} / v_{x}-\delta_{f}\right) \\
F_{y 34}=C_{r}\left(\beta-l_{r} \dot{\psi} / v_{x}\right)
\end{gathered}
$$

where $\beta=v_{y} / v_{x}$. In the presented study, $C_{f}=-87 \mathrm{kN} / \mathrm{rad}$ and $C_{r}=-69 \mathrm{kN} / \mathrm{rad}$ are chosen (the road friction $\mu=0.8$ ).

From Equations (25)-(28), it can be deduced that

$$
\delta_{f}=\left(\frac{L}{v_{x}^{2}}-\frac{l_{r} m}{L C_{f}}+\frac{l_{f} m}{L C_{r}}\right) a_{y}+\left(\frac{1}{L C_{f}}+\frac{1}{L C_{r}}\right) M_{z}
$$


Figure $4 \mathrm{c}$ shows that with a positive $a_{y}$, a negative $M_{z}$ can increase $\delta_{f}$ and cause tyre wear problems due to a large tyre slip angle [26]. However, too large a positive $M_{z}$ can lead to a negative $\delta_{f}$, which could result in counter-steer problems. Therefore, when $a_{y}>0$, the front steering angle has been set to be non-negative in the present study, namely $\delta_{f} \geq 0$, and the yaw moment range can be derived from Equation (29).

$$
M_{z} \leq-\left(\frac{L}{v_{x}^{2}}-\frac{l_{r} m}{L C_{f}}+\frac{l_{f} m}{L C_{r}}\right) a_{y} /\left(\frac{1}{L C_{f}}+\frac{1}{L C_{r}}\right)
$$

It is preferable if the front steering angle is not increased to a value higher than that used for equal torque driving and, therefore, without considering the rotational acceleration of the wheel, if the value of $M_{z}$ is not less than that used for equal torque driving.

$$
M_{z} \geq\left(F_{x 4 e}+F_{x 2 e}-F_{x 1 e}-F_{x 3 e}\right) t_{w} / 2
$$

where $F_{x i e}=\left(T_{\text {all }} / 4-F_{z i} f_{r r} R_{0}\right) / R_{0}$. Following the same rule with a negative $a_{y}$, firstly, when $a_{y}<0$, $\delta_{f} \leq 0$, then

$$
M_{z} \geq-\left(\frac{L}{v_{x}^{2}}-\frac{l_{r} m}{L C_{f}}+\frac{l_{f} m}{L C_{r}}\right) a_{y} /\left(\frac{1}{L C_{f}}+\frac{1}{L C_{r}}\right)
$$

Secondly, it is perferable if the absolute value of the steering angle is not increased to a value higher than that used for equal torque steering and the value of $M_{z}$ is smaller than that used for equal torque driving.

$$
M_{z} \leq\left(F_{x 4 e}+F_{x 2 e}-F_{x 1 e}-F_{x 3 e}\right) t_{w} / 2
$$

The lateral acceleration $a_{y}$ equals zero during straight driving or when the vehicle changes its turning direction. The yaw moment $M_{z}$ can then follow the equal torque driving values in the following equation:

$$
M_{z}=\left(F_{x 4 e}+F_{x 2 e}-F_{x 1 e}-F_{x 3 e}\right) t_{w} / 2
$$

\subsection{Offline Torque Distribution Rules}

The optimisation of $M_{z}$ and the torque distribution can be performed at two levels. The first level concerns optimisation of the torque distribution under each $M_{z}$ and the second level concerns optimisation of all the $M_{z}$. However, applying level one and level two would cost a great deal of calculation time. In Figures 4e, 5c, 6e and 7c, it can be seen that the torque distribution follows certain rules. With the pre-known information of the motor efficiency maps, it is worth exploring offline torque distribution rules.

Since the longitudinal slip ratio is usually small, from Equation (6), it is assumed that $\omega_{1} \approx \omega_{3}$ and $\omega_{2} \approx \omega_{4}$. The optimisation goal expressed in Equation (21), can be reformulated as

$$
\begin{aligned}
P & =\left[\frac{1+\operatorname{sign}\left(T_{1}\right)}{2} \frac{T_{1}}{\eta\left(T_{1}\right)}+\frac{1-\operatorname{sign}\left(T_{1}\right)}{2} T_{1} \eta\left(T_{1}\right)\right] \omega_{1}+\left[\frac{1+\operatorname{sign}\left(T_{3}\right)}{2} \frac{T_{3}}{\eta\left(T_{3}\right)}+\frac{1-\operatorname{sign}\left(T_{3}\right)}{2} T_{3} \eta\left(T_{3}\right)\right] \omega_{1} \\
& +\left[\frac{1+\operatorname{sign}\left(T_{2}\right)}{2} \frac{T_{2}}{\eta\left(T_{2}\right)}+\frac{1-\operatorname{sign}\left(T_{2}\right)}{2} T_{2} \eta\left(T_{2}\right)\right] \omega_{2}+\left[\frac{1+\operatorname{sign}\left(T_{4}\right)}{2} \frac{T_{4}}{\eta\left(T_{4}\right)}+\frac{1-\operatorname{sign}\left(T_{4}\right)}{2} T_{4} \eta\left(T_{4}\right)\right] \omega_{2}
\end{aligned}
$$

The absolute torque change rate for the energy-efficient DYC is set below $500 \mathrm{Nm} / \mathrm{s}$ to get a smooth yaw moment output for the studied manoeuvres. The tyre workload usage is kept smaller than 1. Besides, the equality constraints in Equations (36) and (37) should also be met.

$$
\begin{gathered}
T_{1}+T_{2}+T_{3}+T_{4}=T_{a l l} \\
\left(\frac{T_{4}-F_{z 4} f_{r r} R_{0}}{R_{0}}+\frac{T_{2}-F_{z 2} f_{r r} R_{0}}{R_{0}}-\frac{T_{1}-F_{z 1} f_{r r} R_{0}}{R_{0}}-\frac{T_{3}-F_{z 3} f_{r r} R_{0}}{R_{0}}\right) \frac{t_{w}}{2}=M_{z}
\end{gathered}
$$


where $T_{\text {all }}$ is from the PID velocity controller. Further,

$$
\begin{aligned}
& T_{1}+T_{3}=\frac{1}{2}\left[T_{\text {all }}-M_{z} \frac{2 R_{0}}{t_{w}}-\left(F_{z 4}+F_{z 2}-F_{z 1}-F_{z 3}\right) f_{r r} R_{0}\right] \\
& T_{2}+T_{4}=\frac{1}{2}\left[T_{\text {all }}+M_{z} \frac{2 R_{0}}{t_{w}}+\left(F_{z 4}+F_{z 2}-F_{z 1}-F_{z 3}\right) f_{r r} R_{0}\right]
\end{aligned}
$$

Taking $T_{1}$ and $T_{3}$ for example, $T_{13}=T_{1}+T_{3}\left(T_{2}\right.$ and $T_{4}$ follow the same rule as $T_{1}$ and $T_{3}$ ). The best distribution of $T_{1}$ and $T_{3}$ based on $T_{13}$ for Motor I, Motor II and the motor in Chen and Wang [8] can be seen in Figure 9a-c respectively. Figure 9a shows that the rule-based control of Motor I can be described as

$$
\left\{\begin{array}{l}
T_{1}=T_{3}=T_{13} / 2 \quad-250 \mathrm{Nm} \leq T_{13} \leq-84 \mathrm{Nm} \\
T_{1}=0, T_{3}=T_{13} \quad-84 \mathrm{Nm}<T_{13} \leq 88 \mathrm{Nm} \\
T_{1}=T_{3}=T_{13} / 2 \quad 88 \mathrm{Nm}<T_{13} \leq 500 \mathrm{Nm}
\end{array}\right.
$$

When $T_{13}$ is in the range of $[-84,88] \mathrm{Nm}$, only $T_{3}$ is used. Otherwise, $T_{1}$ and $T_{3}$ divide $T_{13}$ equally. Figure $9 \mathrm{~b}$ shows that the rule-based control of Motor II can be described as

$$
\left\{\begin{array}{l}
T_{1}=T_{3}=T_{13} / 2 \quad-400 \mathrm{Nm} \leq T_{13} \leq-136 \mathrm{Nm} \\
T_{1}=0, T_{3}=T_{13} \quad-136 \mathrm{Nm}<T_{13} \leq 142 \mathrm{Nm} \\
T_{1}=T_{3}=T_{13} / 2 \quad 142 \mathrm{Nm}<T_{13} \leq 800 \mathrm{Nm}
\end{array}\right.
$$

The change rate of $T_{i}$ and $\delta_{f}$ are limited as

$$
\left\{\begin{array}{l}
\left|\dot{T}_{i}\right| \leq 500 \mathrm{Nm} / \mathrm{s} \\
\left|\dot{\delta}_{f}\right| \leq 20 \text { degree } / \mathrm{s}
\end{array}\right.
$$

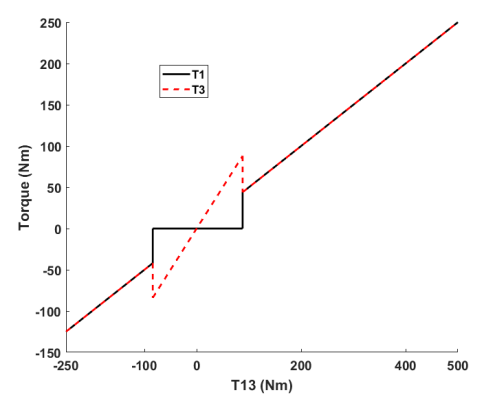

(a)

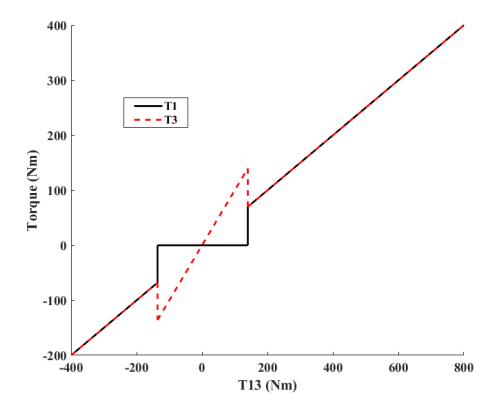

(b)

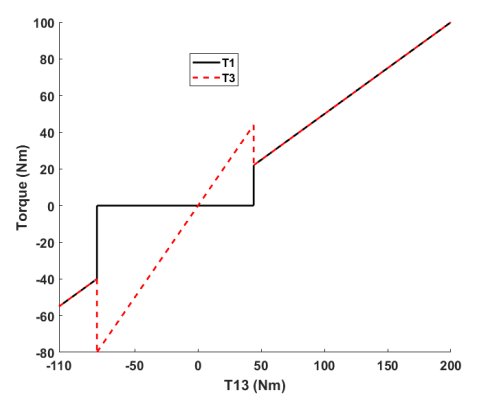

(c)

Figure 9. Offline torque distribution; (a) Motor I; (b) Motor II; (c) Motor in Chen and Wang [8].

\subsection{Controller Structure}

With the input of $T_{\text {all }}$ and $M_{z}$, the torque distribution can follow the offline rules presented in Figure 9. In the $M_{z}$ range $\left(M_{z \min }, M_{z \min }\right)$, the Golden Section Search method is used to search for the best $M_{z}$ to reach the minimal power consumption. This search method is one-dimensional, can greatly reduce the calculation time [27] and has been used online in work [28]. Optimizing the $M_{z}$ in the range of $\left(M_{z \min }, M_{z \min }\right)$ is the only online optimization in the structure and only demands small calculation task. The structure of the controller is shown in Figure 10. As is shown in Figure 10, the $M_{z}$ range $\left(M_{z \min }, M_{z \max }\right)$ can provide more feasibility than the hierarchical structure studied before [8-13] in which $M_{z}$ is a fixed value under each time step. 


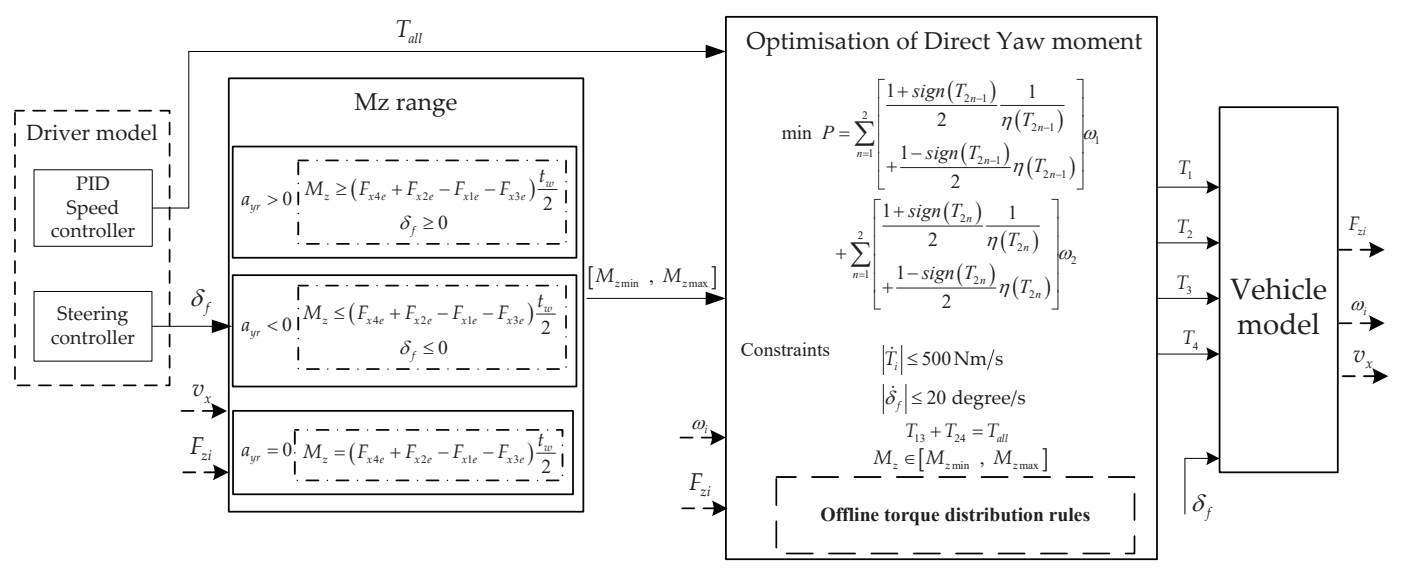

Figure 10. The structure of the controller.

\subsection{Stability DYC}

The function of the stability DYC is to track the desired yaw rate. From the bicycle model [22], the reference yaw rate $\dot{\psi}_{r}$ as a function of $\delta_{f}$ can be expressed as

$$
\dot{\psi}_{r}=\frac{v_{x}}{L+\frac{m v_{x}^{2}}{L}\left(\frac{l_{f}}{C_{r}}-\frac{l_{r}}{C_{f}}\right)} \delta_{f}
$$

The sliding mode control is used to track the reference yaw rate and the sliding surface is designed as

$$
e=\dot{\psi}-\dot{\psi}_{r}+k_{1} \int\left(\dot{\psi}-\dot{\psi}_{r}\right) d t
$$

The reaching law is designed to be $\dot{e}+k_{2} \operatorname{sign}(\mathrm{e})=0$, where $k_{2}>0$. Then the stability $M_{z}$ can be

$$
M_{z}=I_{z}\left(\ddot{\psi}_{r}-k_{1}\left(\dot{\psi}-\dot{\psi}_{r}\right)-k_{2} \operatorname{sign}(\mathrm{e})\right)-\left(F_{y 12} l_{f}-F_{y 34} l_{r}\right)
$$

The torque distribution of $T_{13}$ and $T_{24}$ under stability DYC also follows the offline torque distribution rule proposed above.

\section{Simulation Results during Continuous Driving}

In the simulation performed in the present study, the road friction $\mu$ is chosen to be 0.8 . To verify the effectiveness of the controller, three driving manoeuvres are tested. First, the ISO 3888-1 double lane change manoeuvre [29] at a constant velocity of $50 \mathrm{~km} / \mathrm{h}$ is simulated. Subsequently, an extended double lane change for light manoeuvres at constant velocity $80 \mathrm{~km} / \mathrm{h}$ is designed and simulated. During normal driving, the average driver generally drives with a lateral acceleration below $4 \mathrm{~m} / \mathrm{s}^{2}$ [16] (high friction road), which can be considered as a light manoeuvre. ISO $3888-1$ at $80 \mathrm{~km} / \mathrm{h}$ is a severe manouvre, therefore, an extended double lane change is designed for $80 \mathrm{~km} / \mathrm{h}$. Then a manoeuvre is designed and simulated which involves a longitudinal acceleration of $0.6 \mathrm{~m} / \mathrm{s}^{2}$ starting from a velocity of $50 \mathrm{~km} / \mathrm{h}$ for the ISO 3888-1 manoeuvre. The shape of the double lane change is shown in Figure 11. The parameters for the ISO 3888-1 and extended double lane change manoeuvres are shown in Table 3. During acceleration in the ISO 3888-1 double lane change manoeuvre, first, the vehicle maintains a velocity of $50 \mathrm{~km} / \mathrm{h}$, after which it accelerates with a longitudinal acceleration of $0.6 \mathrm{~m} / \mathrm{s}^{2}$ from $X=15 \mathrm{~m}$ and then maintains a constant velocity from $X=95 \mathrm{~m}$ after exiting the cornering. 


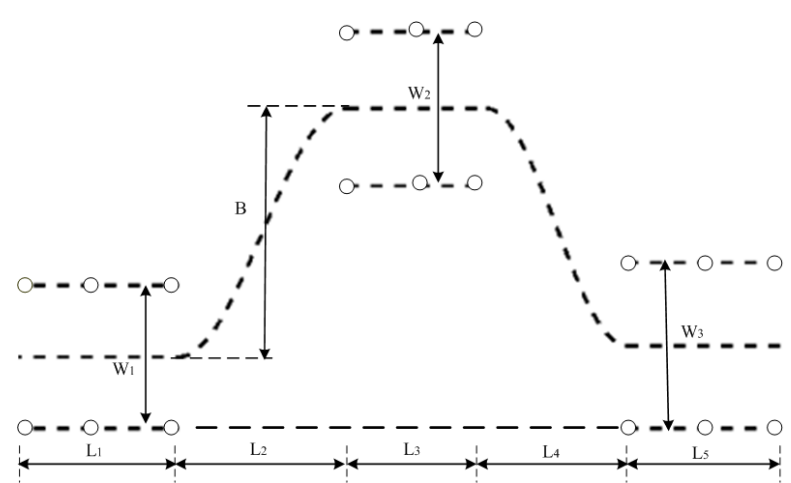

Figure 11. Double lane change manoeuvre.

Table 3. Path parameters.

\begin{tabular}{cccccccccc}
\hline Parameter & $\boldsymbol{L}_{\mathbf{1}}(\mathbf{m})$ & $\boldsymbol{L}_{\mathbf{2}}(\mathbf{m})$ & $\boldsymbol{L}_{\mathbf{3}}(\mathbf{m})$ & $\boldsymbol{L}_{\mathbf{4}}(\mathbf{m})$ & $\boldsymbol{L}_{\mathbf{5}}(\mathbf{m})$ & $\boldsymbol{W}_{\mathbf{1}}(\mathbf{m})$ & $\boldsymbol{W}_{\mathbf{2}}(\mathbf{m})$ & $\boldsymbol{W}_{\mathbf{3}}(\mathbf{m})$ & $\boldsymbol{B}(\mathbf{m})$ \\
\hline ISO3888-1 & 15 & 30 & 25 & 25 & 30 & 2.06 & 2.31 & 2.39 & 3.58 \\
Extended & 15 & 60 & 25 & 50 & 30 & 2.06 & 2.31 & 2.39 & 3.58 \\
\hline
\end{tabular}

Four kinds of torque distribution are simulated, namely 2WETD, 4WETD, stability DYC and active energy-efficient DYC. Motor I and Motor II are simulated, separately. For each comparison, the PID speed controller and multi-point preview steering model have the same parameters. Besides, the vehicle follows the same reference velocity change and the same reference path allowing power consumption to be compared.

The driver model takes the central dotted line in Figure 11 as the reference path which is designed as

$$
\left\{\begin{array}{cc}
Y=0 & 0 \leq X<L_{1} \\
Y=\frac{B}{2}-\frac{B}{2} \cos \left[\frac{\pi}{L_{2}}\left(X-L_{1}\right)\right] & L_{1} \leq X \leq \sum_{i=1}^{2} L_{i} \\
Y=B & \sum_{i=1}^{2} L_{i} \leq X \leq \sum_{i=1}^{3} L_{i} \\
Y=\frac{C}{2}+\frac{D}{2} \cos \left[\frac{\pi}{L_{4}}\left(X-\sum_{i=1}^{3} L_{i}\right)\right] & \sum_{i=1}^{3} L_{i} \leq X \leq \sum_{i=1}^{4} L_{i} \\
Y=0.1 t_{w} & \sum_{i=1}^{4} L_{i} \leq X \leq \sum_{i=1}^{5} L_{i} \\
C=B+0.1 t_{w} ; \quad D=B-0.1 t_{w} &
\end{array}\right.
$$

In order to analyse the potential effect of active energy-efficient DYC on the vehicle's stability, a stability area consisting of the yaw rate and the body slip angle is used. The upper bounds of the yaw rate and the body slip angle were derived from Rajamani [30] and are shown as

$$
\left\{\begin{array}{l}
|\dot{\psi}| \leq 0.85 \mu g / v_{x} \\
|\beta| \leq \operatorname{atan}(0.02 \mu g)
\end{array}\right.
$$

Two stability area examples for a constant velocity, for $v_{x}=50 \mathrm{~km} / \mathrm{h}, \mu=0.8$ and $v_{x}=80 \mathrm{~km} / \mathrm{h}$, $\mu=0.8$, are shown in Figure 12 . 


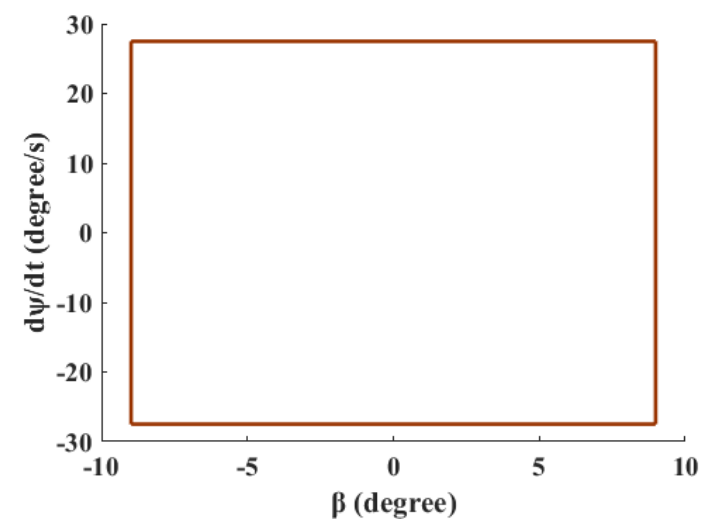

(a)

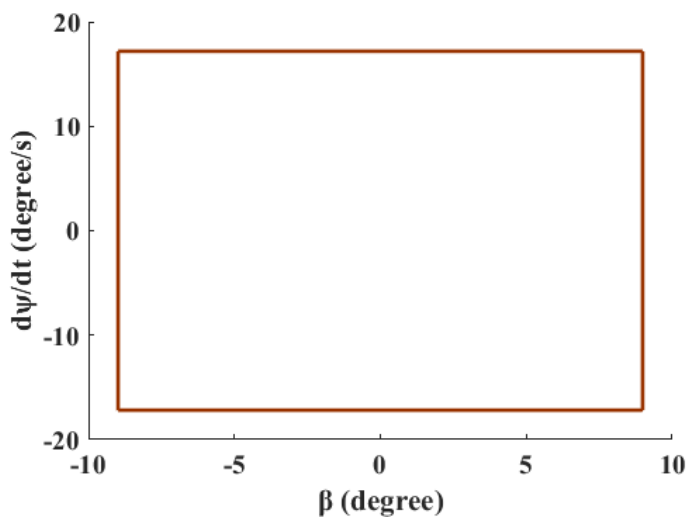

(b)

Figure 12. Stability area; (a) $v_{x}=50 \mathrm{~km} / \mathrm{h}$ and $\mu=0.8 ;(\mathbf{b}) v_{x}=80 \mathrm{~km} / \mathrm{h}$ and $\mu=0.8$.

The average power consumption and the percentage reduction in the power consumption for all the simulated manoeuvres for Motor I and Motor II and for the four torque distributions are listed in Table 4. The energy reduction percentages of 2WETD, stability DYC and energy-efficient DYC compared to 4WETD are listed in Table 4.

Table 4. Average power consumption and the percentage reduction for the simulated driving tests.

\begin{tabular}{|c|c|c|c|c|c|}
\hline & & & & Average Power (kW) & Reduction (\%) \\
\hline \multirow{8}{*}{$v_{x}=50 \mathrm{~km} / \mathrm{h}$} & \multirow{8}{*}{ ISO 3888-1 } & \multirow{4}{*}{ Motor I } & 4WETD & 4.55 & \\
\hline & & & 2WETD & 3.94 & 13.1 \\
\hline & & & Energy-efficient DYC & 3.91 & 14.0 \\
\hline & & & Stability DYC & 4.36 & 4.1 \\
\hline & & \multirow{4}{*}{ Motor II } & 4WETD & 4.94 & \\
\hline & & & 2WETD & 4.35 & 11.9 \\
\hline & & & Energy-efficient DYC & 3.99 & 19.2 \\
\hline & & & Stability DYC & 4.63 & 6.2 \\
\hline \multirow{8}{*}{$v_{x}=80 \mathrm{~km} / \mathrm{h}$} & \multirow{8}{*}{ Extended } & \multirow{4}{*}{ Motor I } & 4WETD & 9.45 & \\
\hline & & & 2WETD & 8.44 & 10.6 \\
\hline & & & Energy-efficient DYC & 8.44 & 10.6 \\
\hline & & & Stability DYC & 8.62 & 8.7 \\
\hline & & \multirow{4}{*}{ Motor II } & 4WETD & 10.41 & \\
\hline & & & 2WETD & 9.02 & 13.3 \\
\hline & & & Energy-efficient DYC & 8.64 & 17 \\
\hline & & & Stability DYC & 8.96 & 13.9 \\
\hline \multirow{8}{*}{ Acceleration } & \multirow{8}{*}{ ISO 3888-1 } & \multirow{4}{*}{ Motor I } & 4WETD & 15.70 & \\
\hline & & & 2WETD & 16.68 & -6.2 \\
\hline & & & Energy-efficient DYC & 15.22 & 3.0 \\
\hline & & & Stability DYC & 17.94 & -14.2 \\
\hline & & \multirow{4}{*}{ Motor II } & 4WETD & 15.84 & \\
\hline & & & 2WETD & 15.91 & -0.4 \\
\hline & & & Energy-efficient DYC & 15.19 & 4.1 \\
\hline & & & Stability DYC & 16.21 & -2 \\
\hline
\end{tabular}

Except power consumption, 2WETD and 4WETD have the same behaviour. In the following analysis, only 2WETD results are plotted. For each manoeuvre, for example ISO 3888-1 double lane change at $v_{x}=50 \mathrm{~km} / \mathrm{h}$, the parameters of PID and multi-point steering model for 4WETD, 2WETD, energy-efficient DYC and stability DYC are kept the same. 


\subsection{ISO 3888-1 Double Lane Change at a Constant Velocity $v_{x}=50 \mathrm{~km} / \mathrm{h}$}

The simulation results for ISO 3888-1 double lane change with Motor I and a constant velocity, $v_{x}=50 \mathrm{~km} / \mathrm{h}$, are shown in Figure 13. Figure 13a,b show that 2WETD, stability DYC and energy-efficient DYC can follow the same path at the same longitudinal velocity (the path and velocity difference is very small).

Figure 13c shows that the working area for the energy-efficient DYC is almost the same as that for equal torque driving and it is far smaller than the boundaries. Therefore, in this case energy-efficient DYC does not have any potential influence on the vehicle's stability. The stability DYC can achieve even smaller working area than the other methods and it proves that stability DYC can be safer. However, from Figure 13e,f the stability DYC needs high demands of $M_{z}$ and stability DYC costs higher power consumption compared to equal torque driving and energy-efficient DYC.

From Figure 13d, during the straight driving phase, energy-efficient DYC uses torque distribution of 2WETD. After entering the corner, energy-efficient DYC could actively distribute the torques so that the overall energy efficiency could be improved. From Table 4, energy-efficient DYC (3.91 kW) can give an energy saving of $14 \%$ compared to 4 WETD $(4.55 \mathrm{~kW})$, a saving of $0.7 \%$ compared to 2 WETD $(3.94 \mathrm{~kW})$ and $10.3 \%$ compared to stability DYC. Stability DYC costs even higher energy than 2WETD under this light manoevure.

The results for Motor II are shown in Figure 14. The results are similar to those for Motor I. From Table 4 and Figure 14f, it is shown that with Motor II, although energy-efficient DYC can give a more obvious energy saving (19.2\% compared to 4WETD, 8.2\% compared to 2WETD and $13.8 \%$ compared to stability DYC), the overall average power consumptions of Motor II are higher than those of Motor I. The reason for this is that, since the total torque demand is not very high, Motor I can keep a higher efficiency than Motor II.

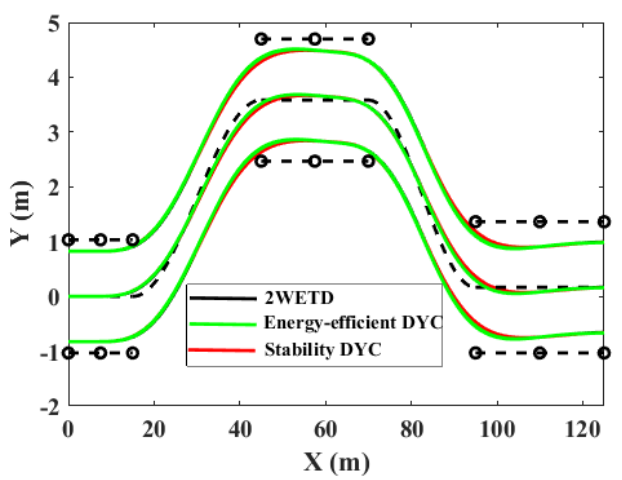

(a)

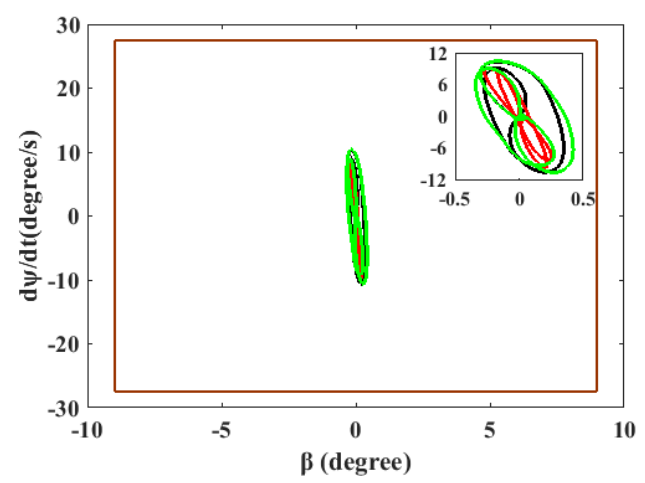

(c)

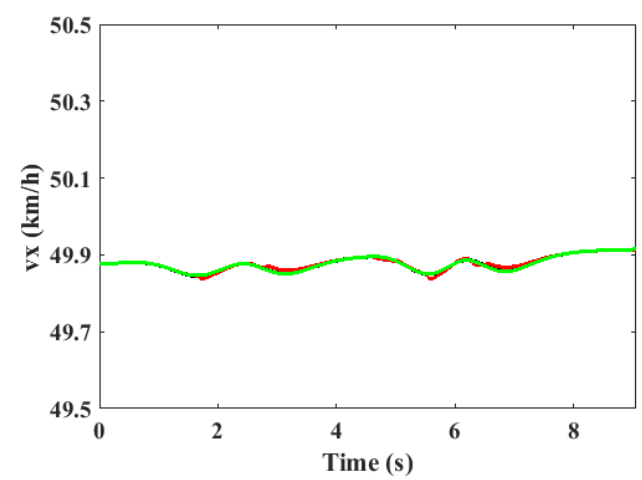

(b)
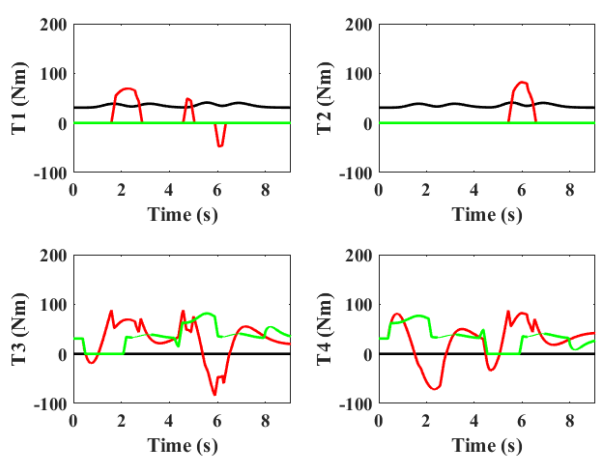

(d)

Figure 13. Cont. 


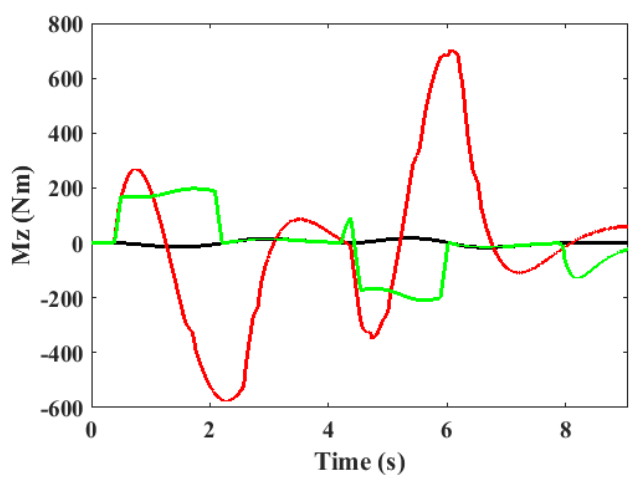

(e)

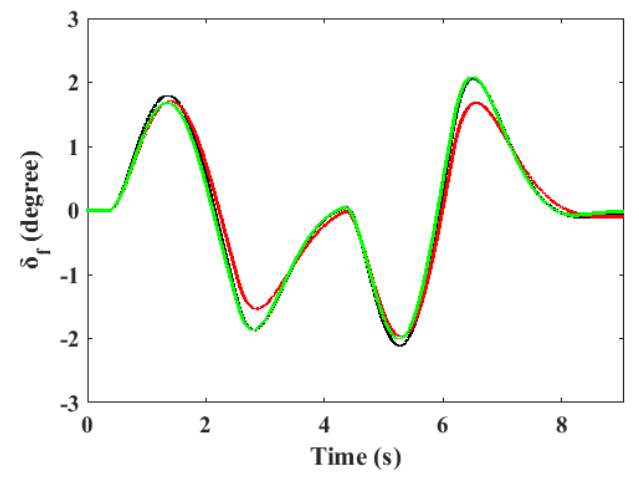

(g)

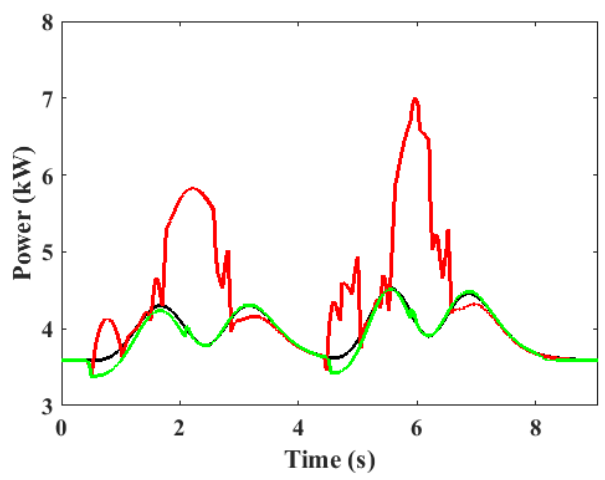

(f)

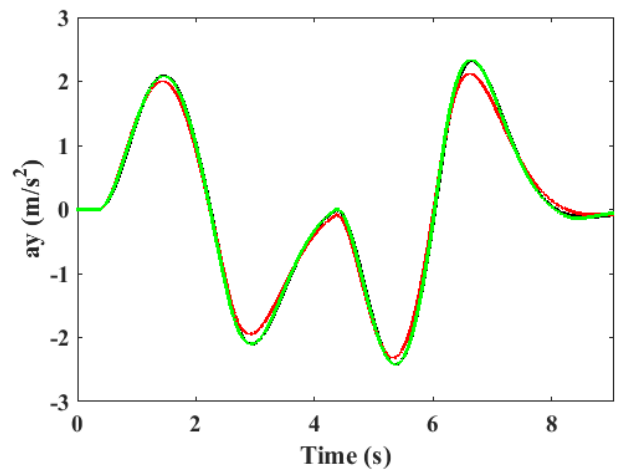

(h)

Figure 13. ISO 3888-1 double lane change with Motor I and $v_{x}=50 \mathrm{~km} / \mathrm{h}$ : (a) Path; (b) Longitudinal velocity; (c) Working area; (d) Wheel torques; (e) Yaw moment; (f) Power; (g) Front steering angle; (h) Lateral acceleration.

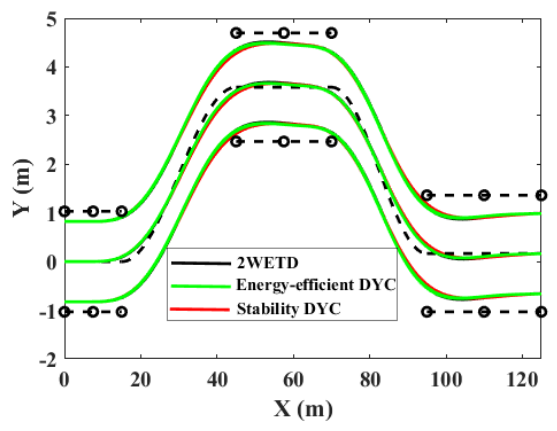

(a)

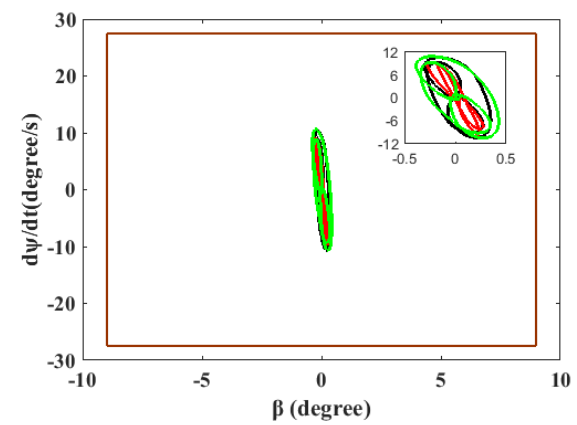

(c)

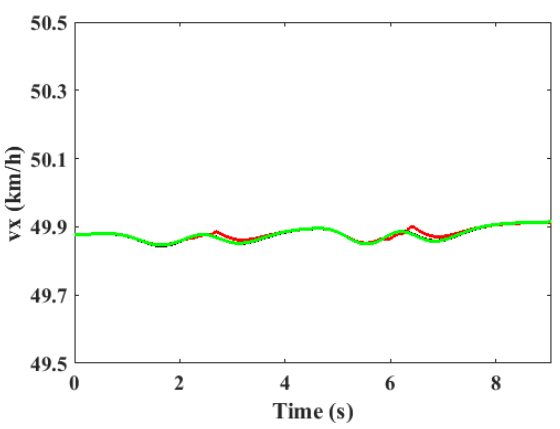

(b)
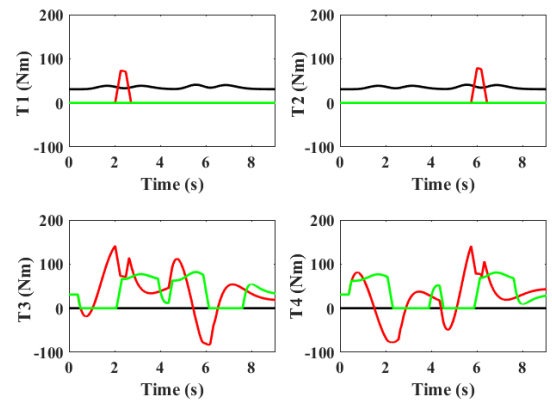

(d)

Figure 14. Cont. 


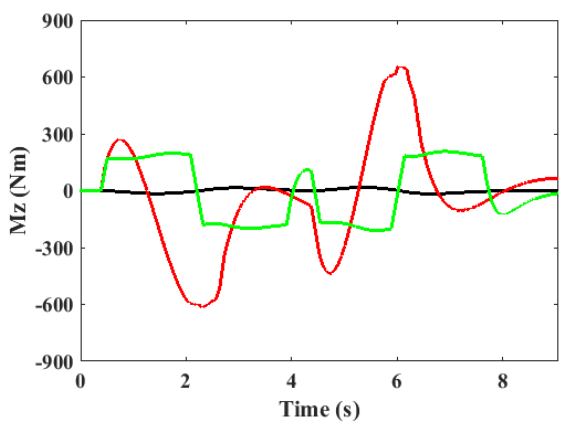

(e)

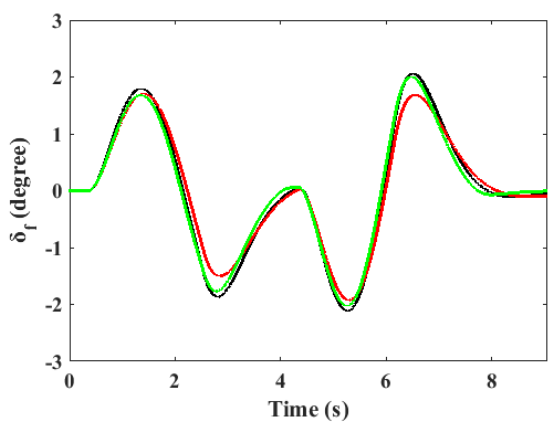

(g)

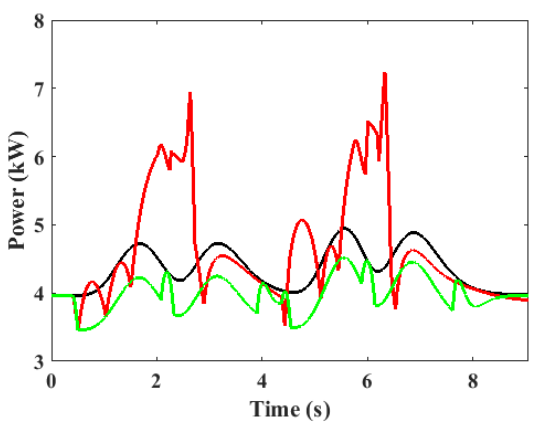

(f)

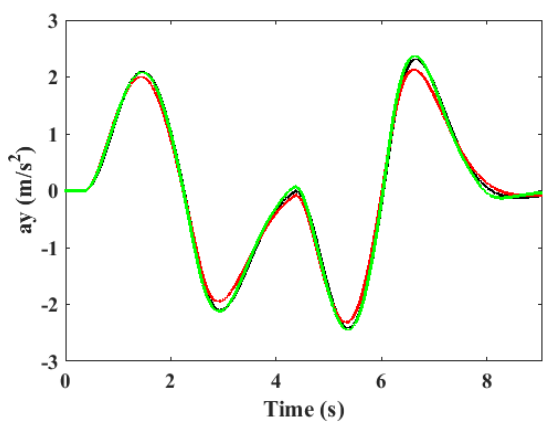

(h)

Figure 14. ISO 3888-1 double lane change with Motor II and $v_{x}=50 \mathrm{~km} / \mathrm{h}$ : (a) Path; (b) Longitudinal velocity; (c) Working area; (d) Wheel torques; (e) Yaw moment; (f) Power; (g) Front steering angle; (h) Lateral acceleration.

\subsection{Extended Double Lane Change at a Constant Velocity $v_{x}=80 \mathrm{~km} / \mathrm{h}$}

During the extended double lane change at a constant velocity, $v_{x}=80 \mathrm{~km} / \mathrm{h}$ and with Motor I, 2WETD, energy-efficient DYC and stability DYC can follow the same path and same velocity from Figure 15a,b. From Figure 15c, these three methods are all safe manoeuvres, energy-efficient DYC has almost the same working area as 2WETD and also stability DYC has smaller working area than the other two. Energy-efficient DYC is shown to adopt 2WETD strategy which is shown in Figure 15d,e. High demand of $M_{z}$ using stability DYC causes higher energy than energy-efficient DYC and 2WETD. Energy-efficient DYC can save $10.6 \%$ energy compared to 4 WETD, $0 \%$ compared to 2 WETD and $2.0 \%$ compared to stability DYC.

The simulation results for Motor II are shown in Figure 16. From Figure 16d,e, energy-efficient DYC adopts a different strategy from 2WETD. In Table 4 and Figure 16f, stability DYC costs less energy than 2WETD. It can also be observed that energy-efficient DYC provides obvious energy savings of $17.0 \%, 4.2 \%$ and $3.5 \%$ compared to 4 WETD, 2 WETD and stability DYC, respectively. In this manoeuvre, stability DYC can consume less power than 2WETD.

\subsection{ISO 3888-1 Double Lane Change with Acceleration}

The simulation results for acceleration during the ISO 3888-1 double lane change with Motor I are shown in Figure 17. At the beginning, when $X \leq 15 \mathrm{~m}$, the velocity is constant at $50 \mathrm{~km} / \mathrm{h}$. When $15 \mathrm{~m}<X \leq 95 \mathrm{~m}$, the vehicle keeps a longitudinal acceleration of $0.6 \mathrm{~m} / \mathrm{s}^{2}$. The velocity $v_{x}=61 \mathrm{~km} / \mathrm{h}$ after acceleration is used to calculate the stability area and it can be seen in Figure 17c that 2WETD and energy-efficient DYC have a similar working area. Also the working areas are far smaller than the boundaries. Therefore, energy-efficient DYC does not have a potential influence on the vehicle stability during this acceleration test. The stability DYC can further reduce the working area.

In Figure 17d, it can be observed that during the initial straight driving, energy-efficient DYC adopts 2WETD; at the beginning of cornering, $T_{4}$ is only applied with the use of energy-efficient 
DYC; during cornering with acceleration, the total torque demand is higher than that for driving at a constant velocity and 4WETD is used by energy-efficient DYC; after acceleration, energy-efficient DYC once again uses 2WETD. From Table 4, it is shown that 4WETD consumes less energy than 2WETD. Energy-efficient DYC could provide a 3.0\% energy saving compared to $4 \mathrm{WETD}$, a $8.75 \%$ saving compared to 2 WETD and $15.1 \%$ compared to stability DYC.

Motor II results in Figure 18 are similar to those obtained with Motor I. However, during acceleration, since the total torque is higher, 2WETD, energy-efficient DYC and stability DYC with Motor II exhibit a higher overall motor efficiency than those with Motor I as can be observed in Table 4.

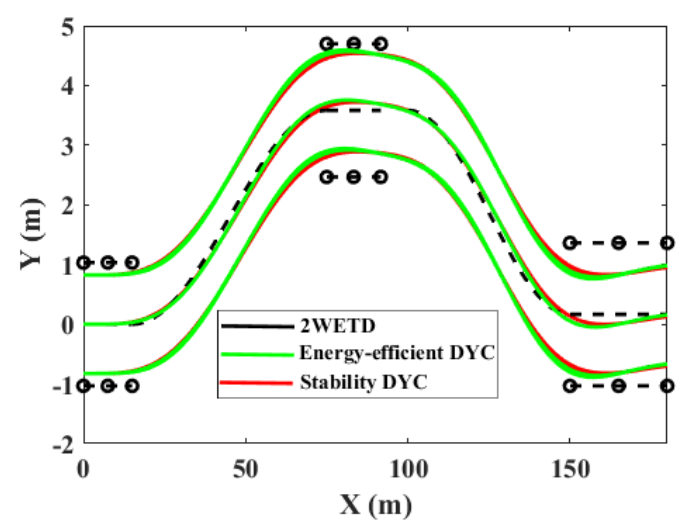

(a)

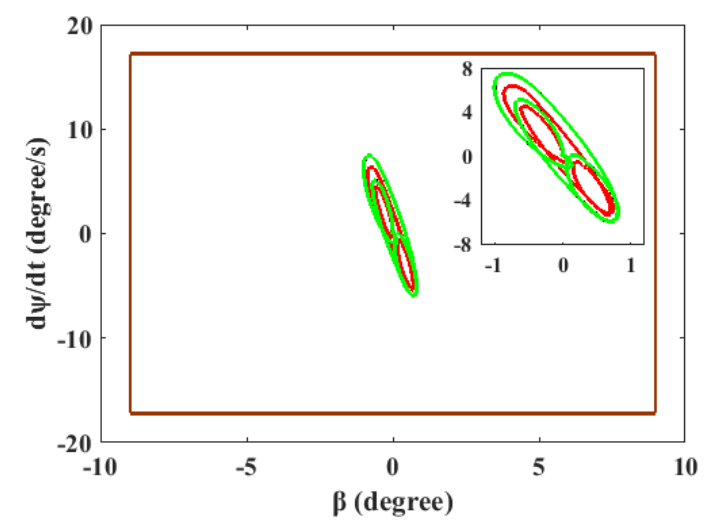

(c)

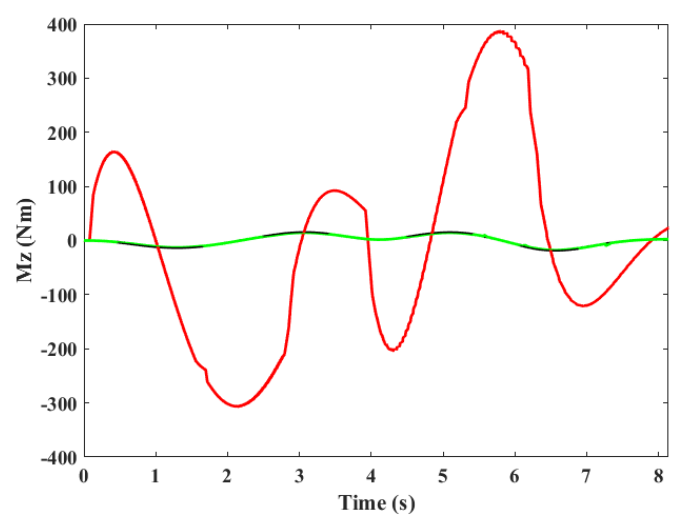

(e)

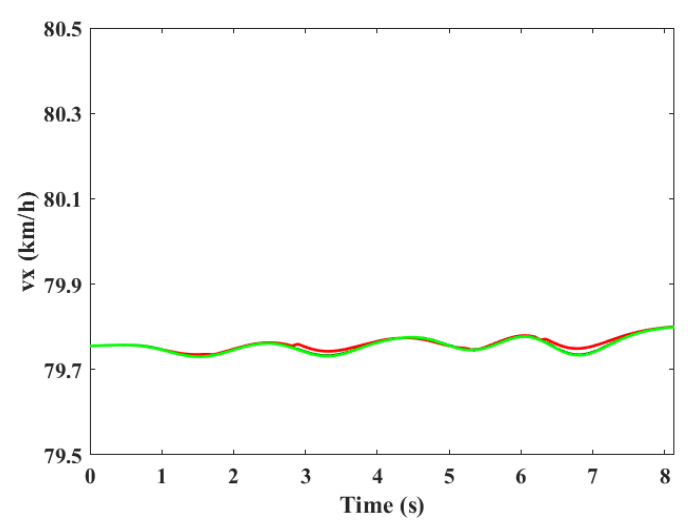

(b)
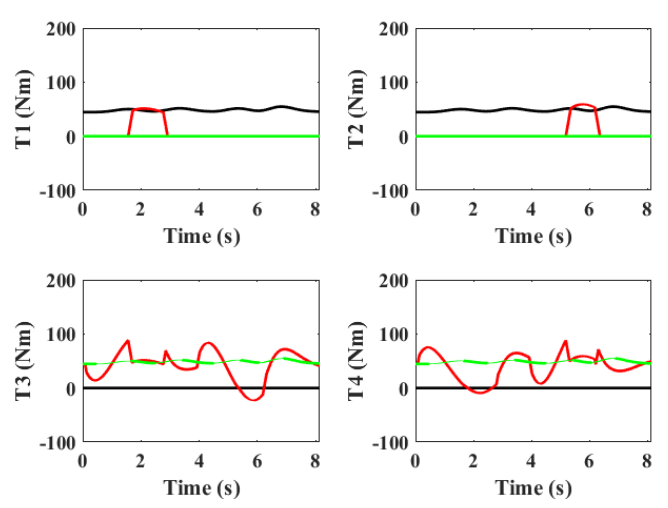

(d)

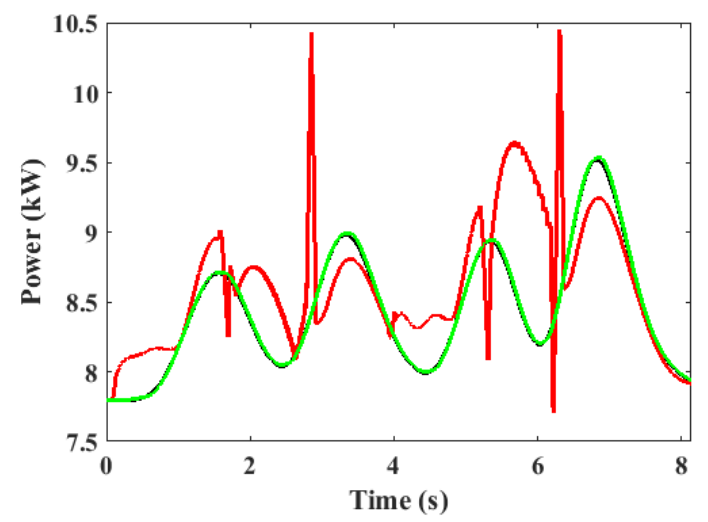

(f)

Figure 15. Cont. 


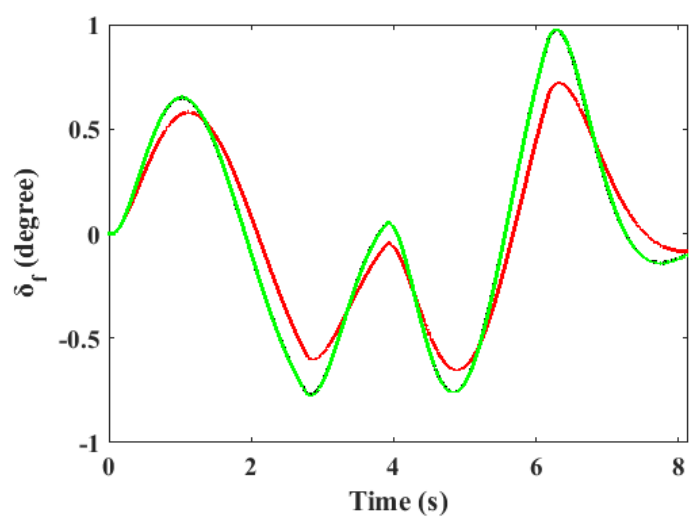

(g)

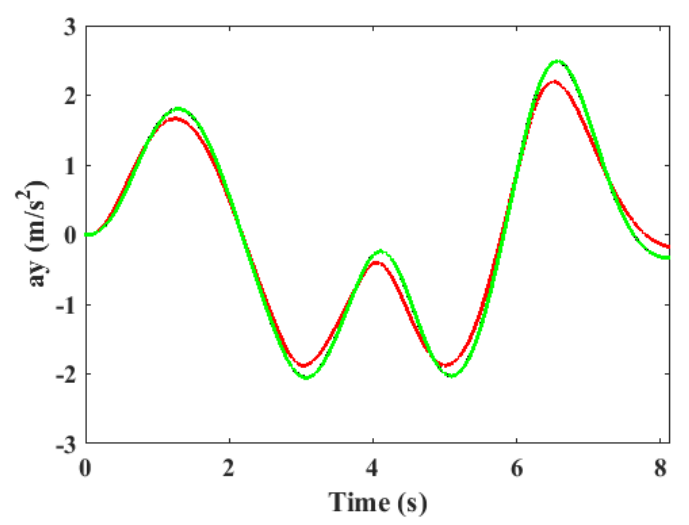

(h)

Figure 15. Extended double lane change with Motor I and $v_{x}=80 \mathrm{~km} / \mathrm{h}$ : (a) Path; (b) Longitudinal velocity; (c) Working area; (d) Wheel torques; (e) Yaw moment; (f) Power; (g) Front steering angle; (h) Lateral acceleration.

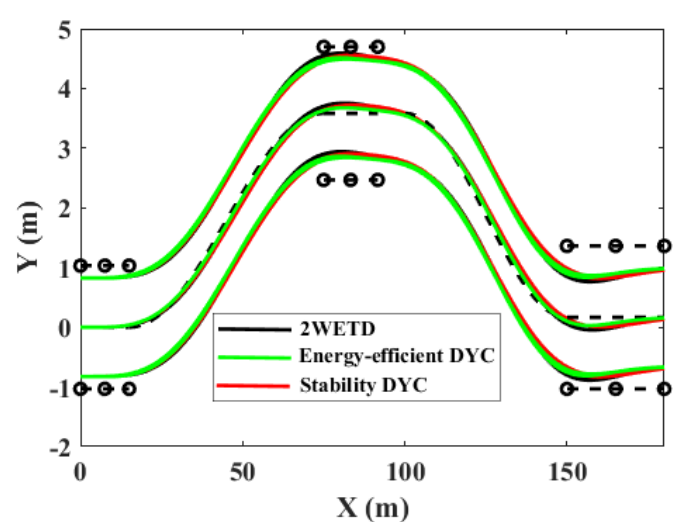

(a)

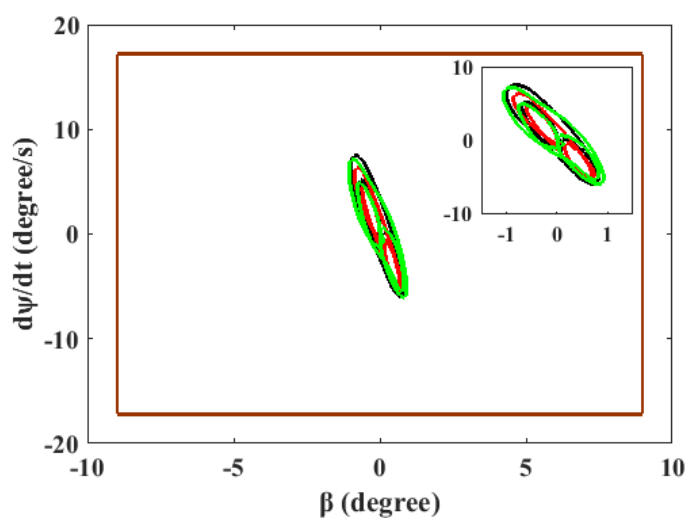

(c)

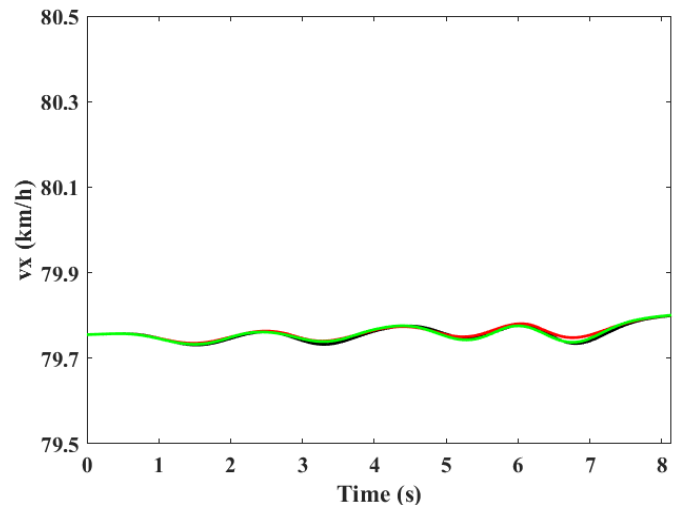

(b)
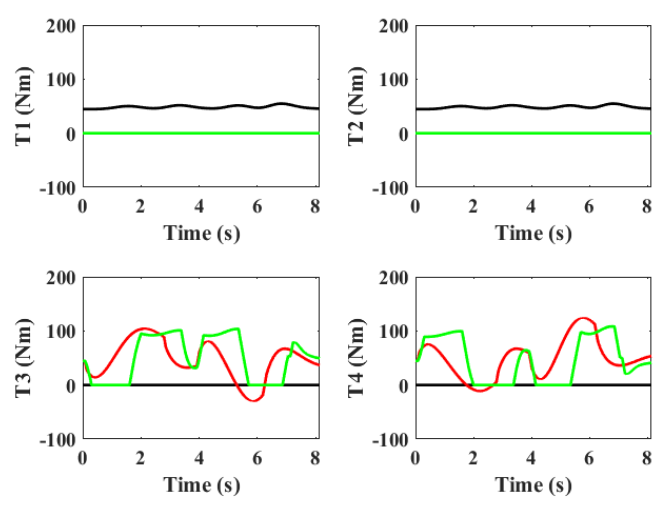

(d)

Figure 16. Cont. 


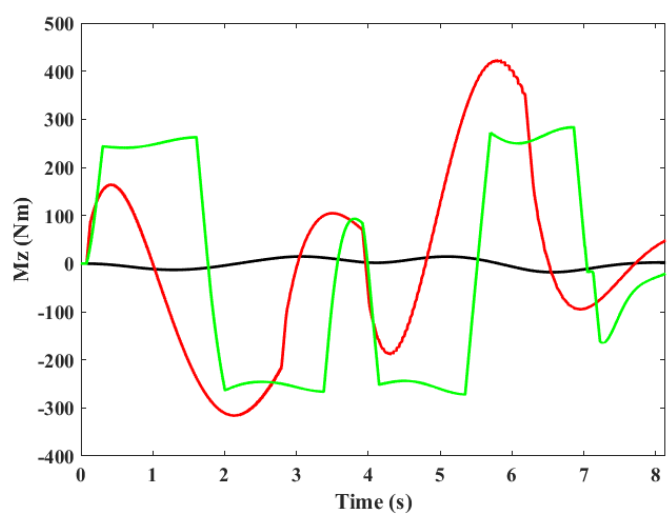

(e)

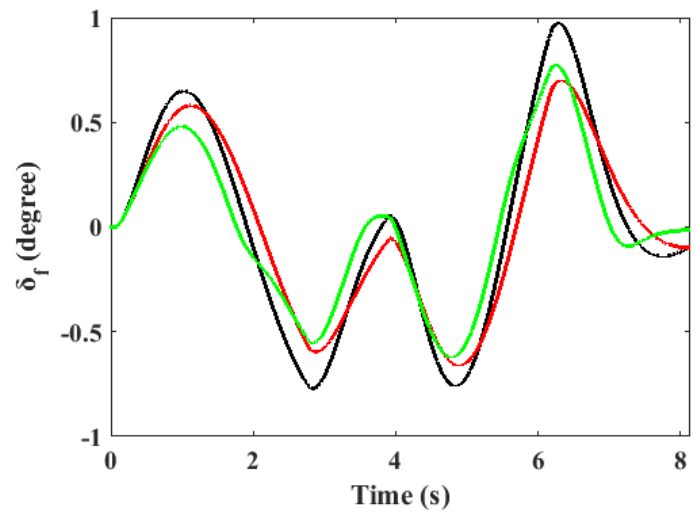

(g)

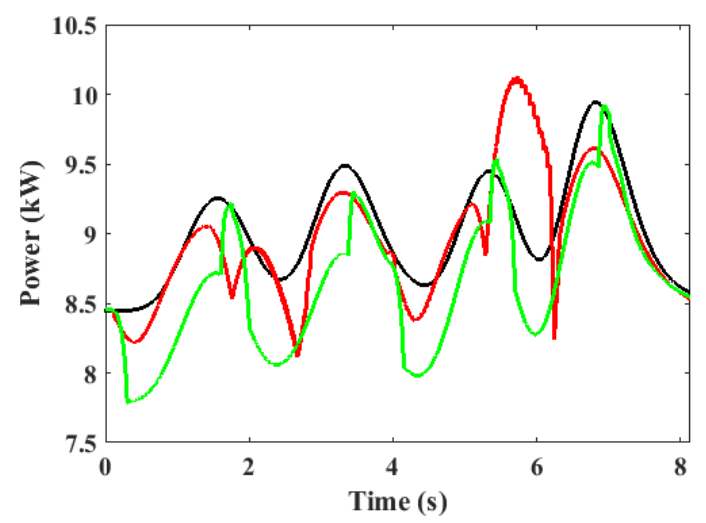

(f)

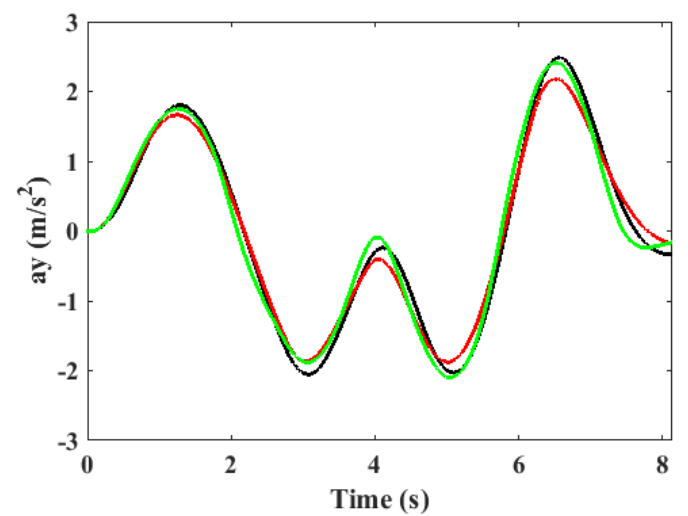

(h)

Figure 16. Extended double lane change with Motor II and $v_{x}=80 \mathrm{~km} / \mathrm{h}$ : (a) Path; (b) Longitudinal velocity; (c) Working area; (d) Wheel torques; (e) Yaw moment; (f) Power; (g) Front steering angle; (h) Lateral acceleration.

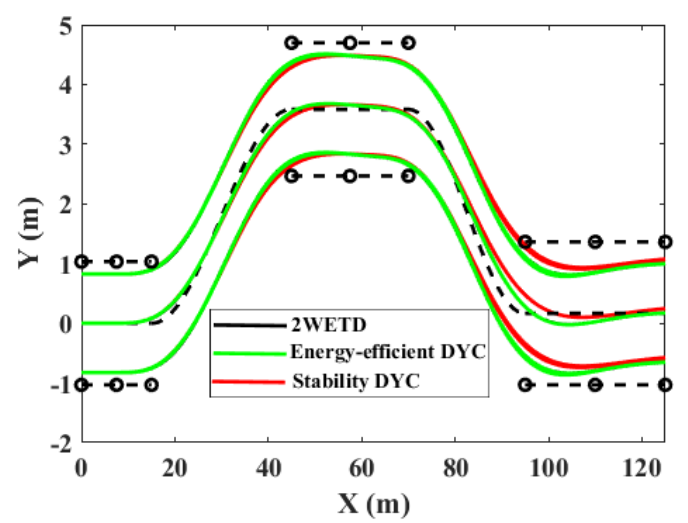

(a)

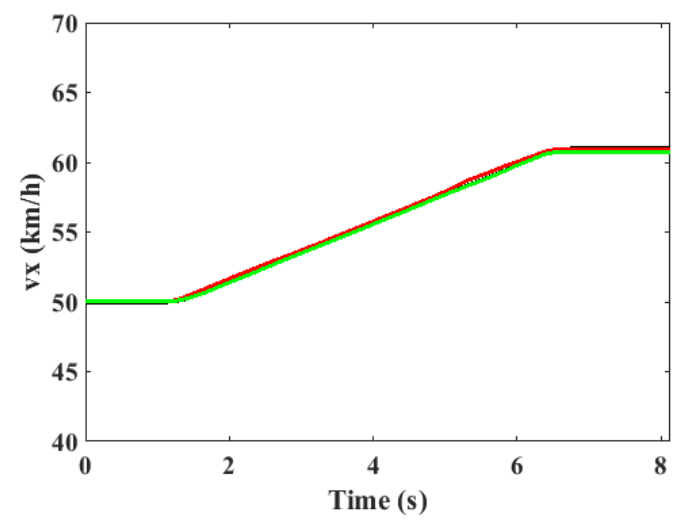

(b)

Figure 17. Cont. 


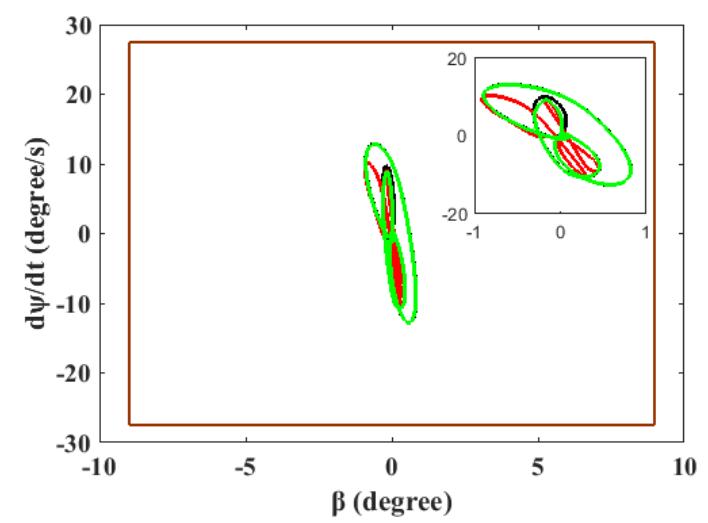

(c)

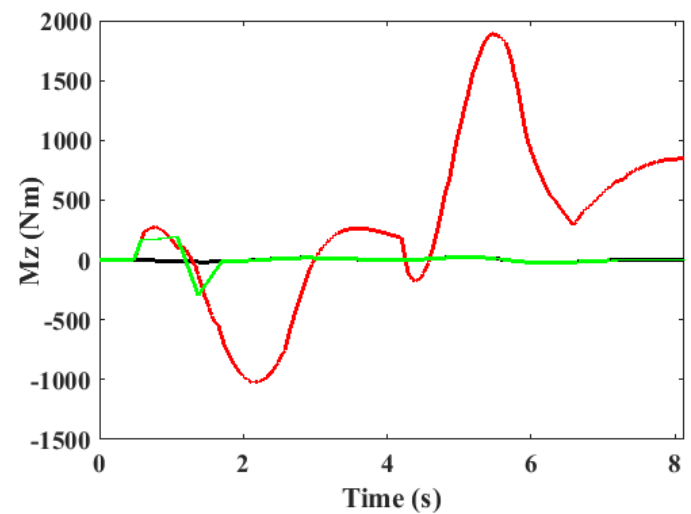

(e)

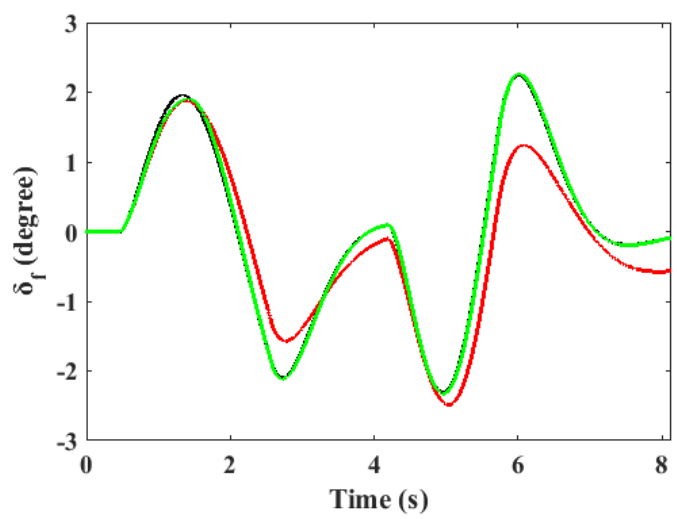

(g)
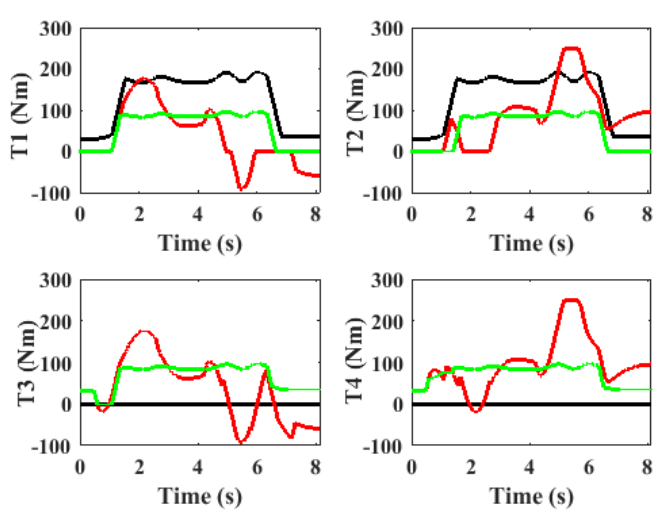

(d)

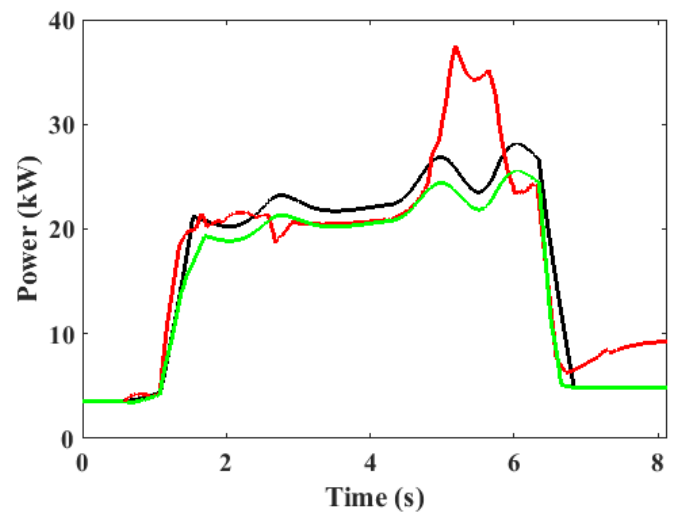

(f)

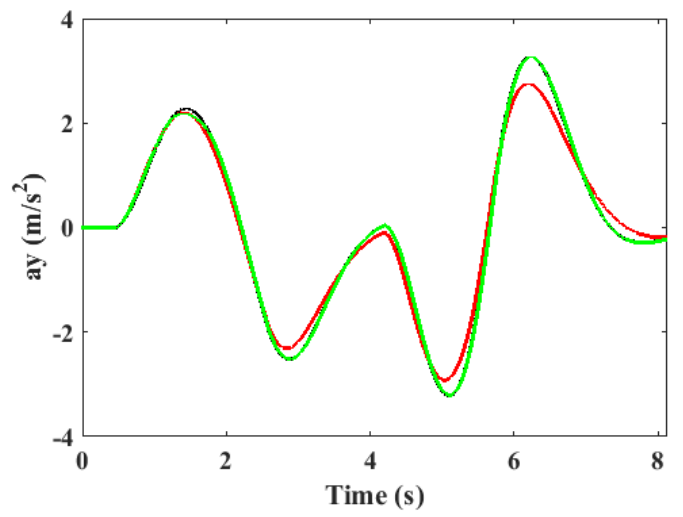

(h)

Figure 17. Acceleration during cornering with Motor I (a) Path; (b) Longitudinal velocity; (c) Working area; (d) Wheel torques; (e) Yaw moment; (f) Power; (g) Front steering angle; (h) Lateral acceleration. 


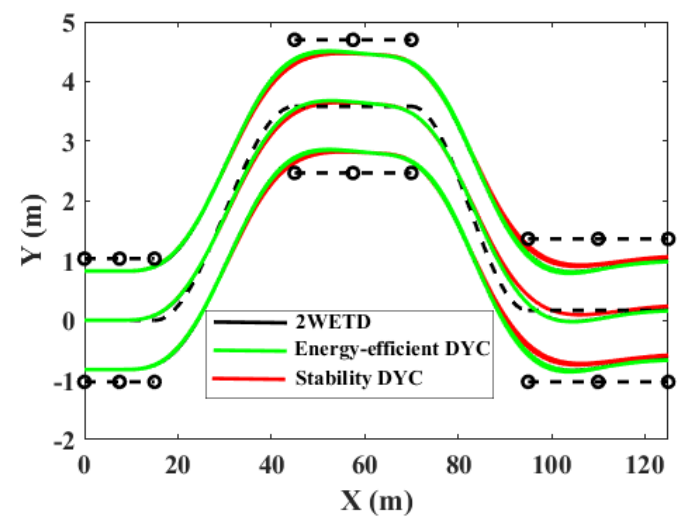

(a)

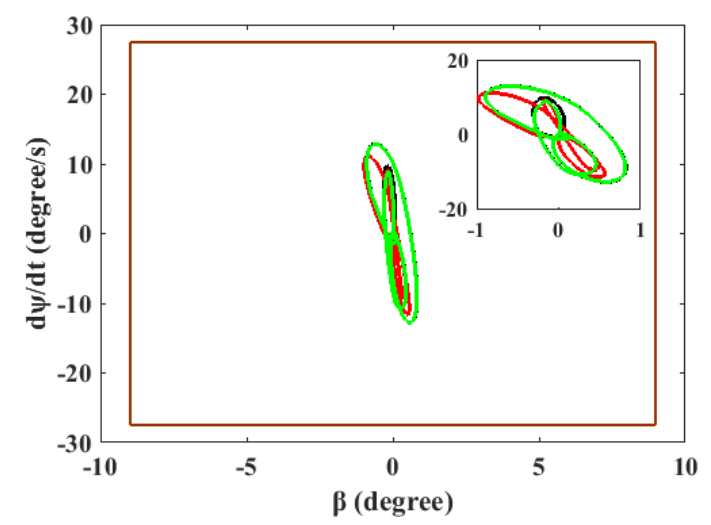

(c)

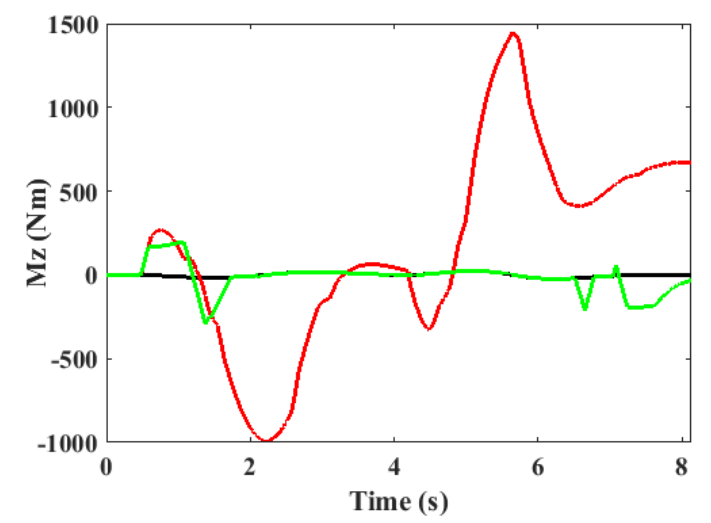

(e)

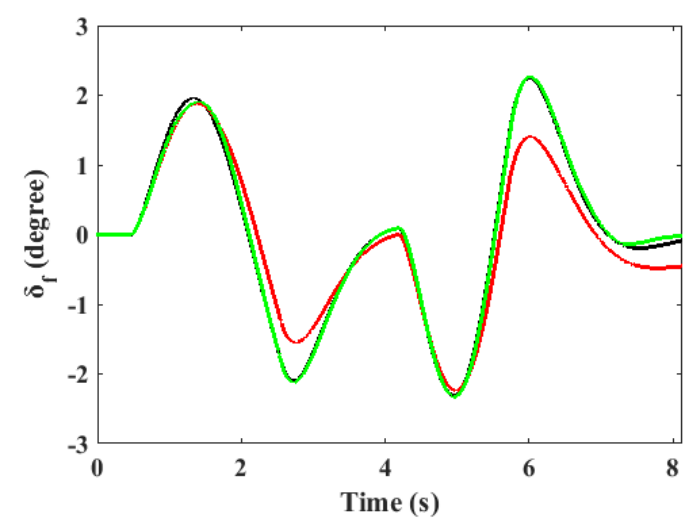

(g)

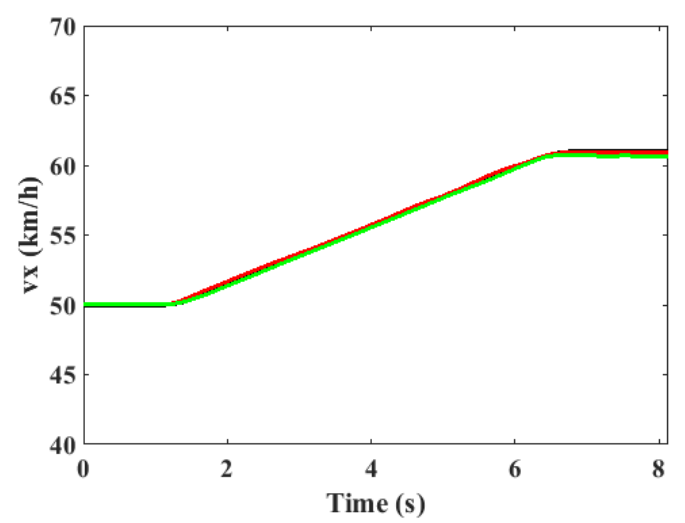

(b)
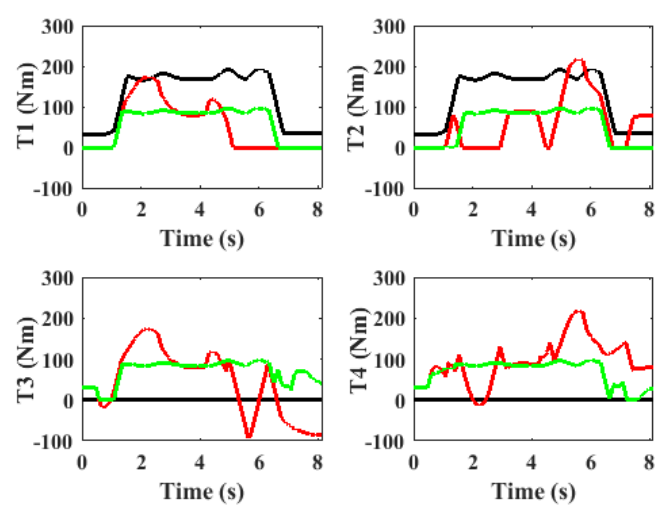

(d)

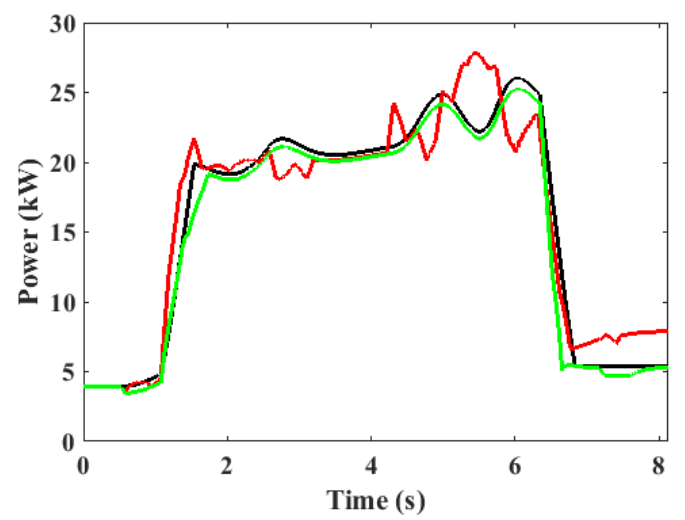

(f)

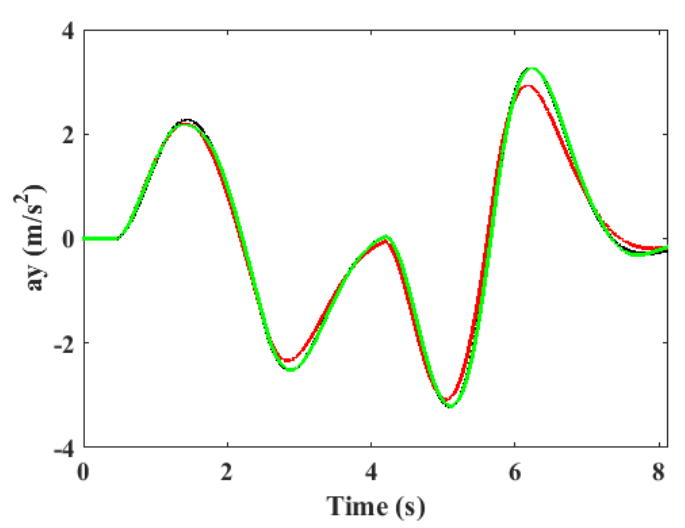

(h)

Figure 18. Acceleration during cornering with Motor II (a) Path; (b) Longitudinal velocity; (c) Working area; (d) Wheel torques; (e) Yaw moment; (f) Power; (g) Front steering angle; (h) Lateral acceleration. 


\section{Conclusions}

The study presented in this paper has studied explored the potential for power consumption reduction of using active DYC in combination with motor efficiency maps, and the results support the use of an active energy-efficient DYC for 4IWM electric vehicles. Two motor efficiency maps, for Motor I and Motor II, were designed. Simulations were performed in which the potential for energy saving using DYC was evaluated through quasi-steady-state cornering. Four control methods are compared: 4WETD, 2WETD, energy-efficient DYC and stability DYC. The results show that it is promising to use energy-efficient DYC which can distribute wheel torques to improve driving efficiency and 3-20\% energy can be saved in the simulated manoeuvres.

In order to explore further the contribution of DYC to energy saving during continuous driving, first, a controller comprising velocity control and direction control was developed. Yaw moment ranges based on the lateral acceleration were then designed and with pre-known information from the motor efficiency maps, offline rules for distributing the torques were thereafter optimised and developed. The yaw moment ranges designed in this study provide more feasibility than other hierarchical structures which have fixed yaw moment value at each time step. Manoeuvres involving two constant velocities and two paths for each velocity using Motors I and II were then simulated. Cornering with acceleration was also simulated. The simulation results show that energy-efficient DYC can actively distribute the torques so that the average power consumption can be reduced. Stability DYC is also considered and analysed. Although, the stability DYC can make the vehicle safer, from prospect of energy saving, it can cost higher power consumption under light manoeuvres.

Since the torque distribution rules are explored offline, the only online optimization procedure is to optimize the energy-efficient $M_{z}$ from the range $\left(M_{z \min }, M_{z \max }\right)$ which is shown in Figure 9. This optimization is a one-dimensional search and does not need tremendous online calculation task. Therefore, it is promising for real time implementation.

In future work, deceleration can be evaluated. During severe driving manoeuvres, stability problems can arise and the stability area of the vehicle can cross the safety boundaries. Energy-saving driving and stability driving can therefore be combined in future studies. The effect of more detailed motor efficiency maps covering all speed ranges can also be studied in the future. Furthermore, offline rules can be explored and compared to online optimisation method in the future work.

Author Contributions: All authors formulated the problem. P.S. designed the controller, made the simulations and wrote the paper. A.S.T., L.D. and J.J. contributed in the analysis and writing. All authors have read and agreed to the published version of the manuscript.

Funding: The authors greatly appreciate the support from China Scholarship Council (CSC), the Centre for ECO2 Vehicle Design at KTH funded by the Swedish Innovation Agency Vinnova (Grant Number 2016-05195) and the strategic research area TRENoP.

Conflicts of Interest: The authors declare no conflict of interest.

\section{References}

1. Ding, S.; Liu, L.; Zheng, W. Sliding mode direct yaw-moment control design for in-wheel electric vehicles. IEEE Trans. Ind. Electron. 2017, 64, 6752-6762. [CrossRef]

2. Yamakado, M.; Takahashi, J.; Saito, S. Comparison and combination of direct yaw-moment control and G-Vectoring control. Veh. Syst. Dyn. 2012, 50, 111-130. [CrossRef]

3. Hu, J.; Wang, Y.; Fujimoto, H.; Hori, Y. Robust yaw stability control for in-wheel motor electric vehicles. IEEE/ASME Trans. Mechatron. 2017, 22, 1360-1370. [CrossRef]

4. Sun, P.; Stensson Trigell, A.; Drugge, L.; Jerrelind, J.; Jonasson, M. Exploring the potential of camber control to improve vehicles' energy efficiency during cornering. Energies 2018, 11, 724. . [CrossRef]

5. Kobayashi, T.; Katsuyama, E.; Sugiura, H.; Ono, E.; Yamamoto, M. Direct yaw moment control and power consumption of in-wheel motor vehicle in steady-state turning. Veh. Syst. Dyn. 2016, 55, 104-120. [CrossRef] 
6. Kobayashi, T.; Katsuyama, E.; Sugiura, H.; Ono, E.; Yamamoto, M. Efficient direct yaw moment control: tyre slip power loss minimisation for four-independent wheel drive vehicle. Veh. Syst. Dyn. 2017, 56, 719-733. [CrossRef]

7. Edrén, J.; Jonasson, M.; Jerrelind, J.; Stensson Trigell, A.; Drugge, L. Energy efficient cornering using over-actuation. Mechatronics 2019, 59, 69-81. [CrossRef]

8. Chen, Y.; Wang, J. Adaptive energy-efficient control allocation for planar motion control of over-actuated electric ground vehicles. IEEE Trans. Control Syst. Technol. 2014, 22, 1362-1373. [CrossRef]

9. Han, Z.; Xu, N.; Chen, H.; Huang, Y.; Zhao, B. Energy-efficient control of electric vehicles based on linear quadratic regulator and phase plane analysis. Appl. Energy 2018, 213, 639-657.10.1016/j.apenergy.2017.09.006. [CrossRef]

10. Zhai, L.; Hou, R.; Sun, T.; Kavuma, S. Continuous steering stability control based on an energy-saving torque distribution algorithm for a four in-wheel-motor independent-drive electric vehicle. Energies 2018, 11, 350. [CrossRef]

11. Dizqah, A.M.; Lenzo, B.; Sorniotti, A.; Gruber, P.; Fallah, S.; Smet, J.D. A fast and parametric torque distribution strategy for four-wheel-drive energy-efficient electric vehicles. IEEE Trans. Ind. Electron. 2016, 63, 4367-4376. [CrossRef]

12. Lenzo, B.; Filippis, G.D.; Dizqah, A.M.; Sorniotti, A.; Gruber, P.; Fallah, S.; Nijs, W.D. Torque distribution strategies for energy-efficient electric vehicles with multiple drivetrains. J. Dyn. Syst. Meas. Control. 2017, 139. [CrossRef]

13. Filippis, G.D.; Lenzo, B.; Sorniotti, A.; Gruber, P.; Nijs, W.D. Energy-efficient torque-vectoring control of electric vehicles with multiple drivetrains. IEEE Trans. Veh. Technol. 2018, 67, 4702-4715. [CrossRef]

14. Suzuki, Y.; Kano, Y.; Abe, M. A study on tyre force distribution controls for full drive-by-wire electric vehicle. Veh. Syst. Dyn. 2014, 52, 235-250, [CrossRef]

15. Li, Y.; Zhang, J.; Lv, C.; Yuan, Y. Comprehensive optimization of dynamics performance and energy consumption for an electric vehicle via coordinated control of SBW and FIWMA. SAE Int. J. Passenger Cars Mech. Syst. 2016, 9, 90-98. [CrossRef]

16. Automotive Handbook, 8th ed; Robert Bosch GmbH, Bentley Publishers: Plochingen, Germany, 2011.

17. Lie, A.; Tingvall, C.; Krafft, M.; Kullgren, A. The effectiveness of ESP (electronic stability program) in reducing real life accidents. Traffic Inj. Prev. 2004, 5, 37-41. [CrossRef]

18. Reif, K. Electronic stability program. In Fundamentals of Automotive and Engine Technology; Springer Fachmedien Wiesbaden: Wiesbaden, Germany, 2014; pp. 194-201. [CrossRef]

19. Pacejka, H. Tire and Vehicle Dynamics, 3rd ed; Elsevier: Amsterdam, The Netherlands, 2012.

20. Giancarlo Genta, L.M. The Automotive Chassis; Springer Netherlands: Dordrecht, The Netherlands, 2008.

21. Guiggiani, M. The Science of Vehicle Dynamics; Springer-Verlag GmbH: Berlin, Germany, 2018.

22. Abe, M. Vehicle Handling Dynamics: Theory and Application; Butterworth-Heinemann: Oxford, UK, 2015.

23. Symonds, P.; Sharp, R.; Casanova, D. A mathematical model for driver steering control, with design, tuning and performance results. Veh. Syst. Dyn. 2000, 33, 289-326. [CrossRef]

24. Schnelle, S.; Wang, J.; Su, H.; Jagacinski, R. A driver steering model with personalized desired path generation. IEEE Trans. Syst. Man Cybern. Syst. 2017, 47, 111-120. [CrossRef]

25. Jalali, K.; Lambert, S.; McPhee, J. Development of a Path-following and a Speed Control Driver Model for an Electric Vehicle. SAE Int. J. Passenger Cars Electron. Electr. Syst. 2012, 5, 100-113. [CrossRef]

26. Braghin, F.; Cheli, F.; Melzi, S.; Resta, F. Sensitivity analysis of the tyre design parameters with respect to tyre wear using a physical tyre model. Veh. Syst. Dyn. 2005, 43, 102-110. [CrossRef]

27. Abidi, M.A.; Gribok, A.V.; Paik, J. Optimization Techniques in Computer Vision; Springer International Publishing: Cham, Germany, 2016. [CrossRef]

28. Ding, X.; Guo, H.; Xiong, R.; Chen, F.; Zhang, D.; Gerada, C. A new strategy of efficiency enhancement for traction systems in electric vehicles. Appl. Energy 2017, 205, 880-891. [CrossRef] [CrossRef]

29. International Organization for Standardization. Passenger Cars-Test Track for a Severe Lane-Change Manoeuvre: Part 1: Double Lane-Change; ISO: Geneva, Switzerland, 2018.

30. Rajamani, R. Vehicle Dynamics and Control, 2nd ed.; Springer: Boston, MA, USA, 2012. [CrossRef]

(C) 2020 by the authors. Licensee MDPI, Basel, Switzerland. This article is an open access article distributed under the terms and conditions of the Creative Commons Attribution (CC BY) license (http:/ / creativecommons.org/licenses/by/4.0/). 